Research Article

\title{
Comparing Hysteretic Energy and Ductility Uniform Annual Failure Rate Spectra for Traditional and a Spectral Shape-Based Intensity Measure
}

\author{
Joel Carvajal, ${ }^{1}$ Edén Bojórquez $\mathbb{D}$, ${ }^{1}$ Sonia Ruiz $\left(\mathbb{D},{ }^{2}\right.$ Juan Bojórquez $\left(\mathbb{D},{ }^{1}\right.$ \\ Alfredo Reyes-Salazar (D), ${ }^{1}$ Ali Rodríguez, ${ }^{2}$ Mauro Niño, ${ }^{2}$ Jorge Ruiz-García, ${ }^{3}$ \\ Francisco López-Almansa, ${ }^{4}$ and José Torres ${ }^{1}$ \\ ${ }^{1}$ Facultad de Ingeniería, Universidad Autónoma de Sinaloa, Culiacán 80040, Mexico \\ ${ }^{2}$ Instituto de Ingeniería, Universidad Nacional Autónoma de México, México 04510, Mexico \\ ${ }^{3}$ Facultad de Ingeniería Civil, Universidad Michoacana de San Nicolás de Hidalgo, Morelia 58040, Mexico \\ ${ }^{4}$ Architecture Technology Department, Technical University of Catalonia, Barcelona 08028, Spain
}

Correspondence should be addressed to Edén Bojórquez; eden@uas.edu.mx and Juan Bojórquez; juanbm@uas.edu.mx

Received 5 October 2021; Revised 10 November 2021; Accepted 12 November 2021; Published 15 December 2021

Academic Editor: Qian Chen

Copyright (C) 2021 Joel Carvajal et al. This is an open access article distributed under the Creative Commons Attribution License, which permits unrestricted use, distribution, and reproduction in any medium, provided the original work is properly cited.

In this study, with the objective to develop a reliability-based seismic design tool, ductility and dissipated hysteretic energy uniform annual failure rate (UAFR) spectra are obtained and compared using the spectral acceleration at first mode of vibration of the structure $S a\left(T_{1}\right)$ and the well-known spectral shape-based intensity measure $I_{N p}$. Notice that this is the first time in the literature that UAFR spectra are obtained for the advanced spectral shape intensity measure $I_{N p}$. For this aim, 110 simulated ground motions recorded from the soft soil of Mexico City were selected due to their large energy amount demanded to the structures; moreover, four elastoplastic hysteretic behavior models are considered for the dynamic analyses with post-yielding stiffness of $0,3,5$, and $10 \%$. It is observed that the use of elasto-perfectly plastic models provided similar UAFR spectra in comparison with hysteretic models with different post-yielding stiffness. This conclusion is valid for the two selected intensity measures. In addition, the lateral resistance required to achieve similar structural reliability levels is larger when the $I_{N p}$ intensity measure is used, especially for buildings with vibration periods equal or larger than the soil period, in such a way that the traditional use of $S a\left(T_{1}\right)$ could provide structures with less structural reliability levels.

\section{Introduction}

One of the main features to design structures subjected to earthquakes is the use of design or response spectra. The spectra provided by the seismic regulations are determined in most of the cases through single-degree-of-freedom (SDOF) systems with elastic behavior subjected to a set of seismic records, which are reduced to account for nonlinear behavior via ductility reduction factors. The current version of Mexico City Building Code (MCBC) and most of the codes around the world use the spectral acceleration at first mode of vibration of the structure $S a\left(T_{1}\right)$ to estimate the design lateral resistance and stiffness demand of buildings under earthquakes and to control the maximum lateral displacement demand. However, it is known that $S a\left(T_{1}\right)$ presents some limitations when it is used as intensity measure due to its lack of efficiency to predict the nonlinear structural response [1-4]. For example, $S a\left(T_{1}\right)$ does not consider the effect of the elongation of the vibration period when nonlinear behavior occurs. For this reason, Bojórquez and Iervolino [5] proposed a spectral shape parameter named $N_{p}$ and the $I_{N p}$ intensity measure toward more efficient parameters. Several researchers have demonstrated the great potential of the $I_{N p}$ intensity measure $[1,6-11]$. In general, the studies have concluded that the most efficient scalar or vector-valued intensity measures are those based on 
the $N_{p}$ spectral shape parameter as in the case of $I_{N p}$. Thus, it is important to provide new design or response spectra based on more efficient parameters such as $I_{N p}$. In addition, another two important issues should be accounted for seismic-resistant design of structures. The first one is the inclusion of plastic deformation demands through energy concepts. The use of energy for this purpose was initially discussed by Housner [12]. This concept has been used by various researchers to propose energy-based methodologies aimed to provide the structure with a capacity higher or equal to that demanded by earthquakes [13-20]. In particular, the hysteretic or normalized hysteretic energy has been selected for energy-based design because it is related to the structural damage [21, 22]. On the other hand, the current seismic designs do not take into account explicitly the specific reliability levels in the designed structures. Most of the regulations around the world are mainly based on studies of SDOF systems with elasto-perfectly plastic hysteretic behavior for seismic design of structures, and they do not guarantee the same failure rate on structures as observed in previous studies [23-25]. The seismic design spectra of structures proposed by current codes are not usually associated with specific reliability levels or annual failure rates [26, 27].

This work is motivated by the need to consider the cumulative damage, the structural reliability level, and efficient ground motion intensity measures for earthquakeresistant design of buildings based on the use of uniform annual failure rate spectra. For this reason, in this study ductility and normalized hysteretic energy uniform annual failure rate spectra based on $I_{N p}$ and $S a\left(T_{1}\right)$ are obtained and compared. To achieve the objectives of this study, nonlinear systems with different post-yielding stiffness, ductility, and normalized hysteretic energy capacities and several structural reliability levels are studied. To compute the uniform annual failure rate spectra, the structures are subjected to 110 simulated narrowband ground motions of the soft soil of the Valley of Mexico, and the results of UAFR spectra are presented for the case of ductility and normalized hysteretic energy. Notice that the study can be expanded using other types of ground motion records, such as those recommended in several works or ground motion selection procedures [28-33]. This study is limited to these seismic records because in order to obtain just one spectrum for a specific intensity measure, ductility value, or hysteretic energy and hysteretic curve, the authors required more than 5 million of nonlinear dynamic analyses, which is a high computational work. In addition, the implications of using simplified models such as the well-known elasto-perfectly plastic behavior to obtain the lateral resistance requirements when the two intensities $S a\left(T_{1}\right)$ vs. $I_{N p}$ are used are estimated. Finally, it is important to say that this is the first time in the literature that UAFR spectra are obtained for the advanced spectral shape intensity measure $I_{N p}$ toward future energy-based seismic design taken into account the structural reliability.

\section{Methodology}

2.1. Estimation of UAFR Spectra. The ductility and hysteretic energy UAFR spectra were estimated via the previous works developed by Esteva [34] and Cornell [35] based on the total probability theorem, where the annual failure rate can be defined as next:

$$
\nu_{F}=\int P(Q \geq 1 \mid y)\left|\frac{\mathrm{d} \nu_{Y}(y)}{\mathrm{d} y}\right| \mathrm{d} y,
$$

where $\left|\mathrm{d} v_{Y}(y) / \mathrm{d} y\right|$ corresponds to the absolute value of the derivative of the site seismic hazard curve; $Q$ expressed the relationship between demand and capacity; and $P(Q \geq 1 \mid y)$ is the conditional probability of failure given a seismic intensity $y$. Notice that the structural failure occurs when the capacity is smaller than demand, and in other words: demand/capacity $=Q \geq 1$

The procedure to compute the UAFR spectra is as follows:

(1) Selection of the structural systems

For this study, four elastoplastic-based hysteretic behaviors are considered for the nonlinear models with different post-yielding stiffness ratios. The first single-degree-of-freedom system selected corresponds to the elasto-perfectly plastic hysteretic behavior, and this model can exhibit a linear elastic behavior until a value of strength called yielding point and then behave in a plastic mode until a maximum displacement is obtained. In addition, three elastoplastic models with different postyielding stiffness ratios corresponding to 3, 5, and $10 \%$ have been selected (see Figure 1).

(2) Selection of the simulated earthquake ground motion records

In the seismic design of structures, it is necessary to have seismic records of different magnitudes, and in a sufficient quantity so that it is possible to characterize, in a precise way, the seismic hazard; for this, it is required to identify and take into account all the seismic sources with potential influence in the study site. Unfortunately, the short time of observation and the lack of instrumentation in many regions make it difficult to obtain such records, particularly for large earthquakes. This has motivated the development of several methodologies of seismic simulation to obtain synthetic records of great magnitude earthquakes $[36,37]$. In particular, the methods of seismic simulation that use a stochastic summation approach with Green's empirical functions (FGE) are widely accepted in structural engineering, due to their easy application to generate synthetic records. Such methodologies have their origin in 1978 thanks to Hartzell [38].

In this study, it was selected to use the methodology developed by Niño et al. [39]. They propose a source model defined by two corner frequencies and a summation scheme divided into two stages $[40,41]$, to obtain more accurate spectra to the conditions that affect Mexico City, as well as to improve the definition of the changes 


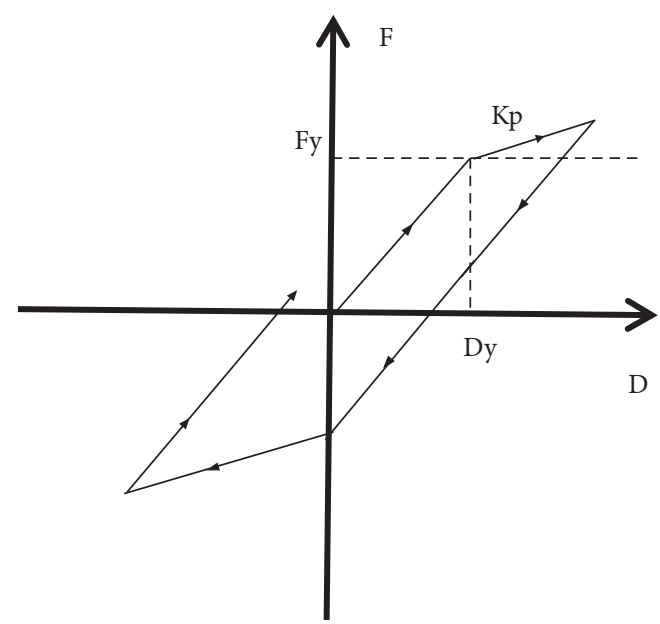

Figure 1: Hysteretic model and cyclic responses of the four analyzed systems, and the nonlinear models correspond to elastoplastic with post-yielding stiffness $K_{\mathrm{p}}=0,3,5$, and $10 \%$.

in the amplitudes, according to the size of the source and the total duration of the seismic event [42]. With this method, 110 seismic records were simulated for different moment magnitudes $M_{\mathrm{w}}$ from 7.2 to 8.2 , with a magnitude increase $\Delta M=0.1$. For the purpose of this study, the record of the seismic event of April 29, 1989, obtained in the SCT station was used as seed for the simulations; in addition, a stress drop $\Delta \sigma=$ 150 bars was considered. The corresponding parameters of moment of magnitude, $M_{\mathrm{w}}$, and the two corner frequencies for each stage for the events employed as seed and each of the simulated magnitudes are presented in Table 1.

The average response spectra of the simulated ground motion records are illustrated in Figure 2 for each selected magnitude. Notice the large amplifications of the pseudo-acceleration in a welldefined region of the spectra $(1.5-2.5 \mathrm{~s})$. Figure 3 shows the elastic pseudo-acceleration response spectra for all the simulated ground motion records and $5 \%$ of damping ratio; moreover, the mean, 25th percentile, and 75th percentile earthquake response spectra also are illustrated.

(3) Selection of the ground motion intensity measures As it was previously indicated, the most used intensity measure by most of the seismic design codes is the spectral acceleration at first mode of vibration (especially for low-rise structures) $[2,5]$, because it is the perfect predictor of the response of elastic single-degree-of-freedom systems and multi-degree-of-freedom systems dominated by the first mode of vibration. Nevertheless, $S a\left(T_{1}\right)$ does not provide information about spectral shape in other regions of the spectrum, which is essential for nonlinear behavior of structures or for which their behavior is dominated by higher modes (modes with periods
TABLE 1: Magnitudes and corner frequencies for each stage for the seismic events used as seed.

\begin{tabular}{lcccc}
\hline & \multicolumn{2}{c}{ First stage } & \multicolumn{2}{c}{ Second stage } \\
$M_{w}$ & $\omega_{a}$ & $\omega_{b}$ & $\omega_{a}$ & $\omega_{b}$ \\
\hline 7.2 & 0.2013 & 3.5899 & 0.2203 & 3.9287 \\
7.3 & 0.1721 & 3.3353 & 0.1939 & 3.7567 \\
7.4 & 0.1471 & 3.0987 & 0.1706 & 3.5922 \\
7.5 & 0.1258 & 2.8789 & 0.1501 & 3.4349 \\
7.6 & 0.1075 & 2.6747 & 0.1320 & 3.2845 \\
7.7 & 0.0919 & 2.4850 & 0.1162 & 3.1407 \\
7.8 & 0.0786 & 2.3088 & 0.1022 & 3.0032 \\
7.9 & 0.0672 & 2.1450 & 0.0899 & 2.8717 \\
8.0 & 0.0574 & 1.9929 & 0.0791 & 2.7460 \\
8.1 & 0.0491 & 1.8515 & 0.0696 & 2.6258 \\
8.2 & 0.0420 & 1.7202 & 0.0613 & 2.5108 \\
\hline
\end{tabular}

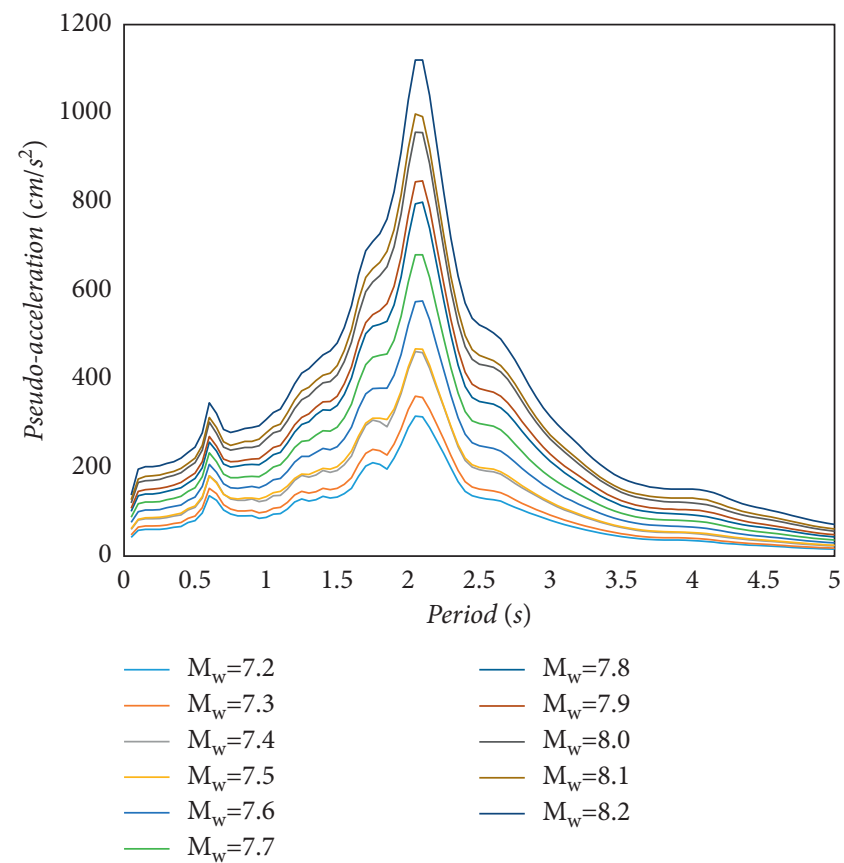

Figure 2: Average response spectra of the selected simulated ground motion records for different moment magnitudes $M w$.

below than $T_{1}$ ). On the other hand, in recent studies some researchers have proposed parameters to define appropriate intensity measures, which are related to the spectral shape due to its relationship with the structural response.

Recently, following the approach to develop spectral shape parameter as intensity measure, Bojórquez and Iervolino [5] proposed the wellknown spectral shape parameter $N_{p}$, which takes into account the nonlinear behavior of the structures by including several points of a response spectrum. The $N_{p}$ spectral shape parameter is defined as the ratio of the geometrical mean between the periods $T_{1}$ and $T_{N}$ $S a_{\text {avg }}\left(T_{1}, \ldots, T_{N}\right)$ normalized with respect to 


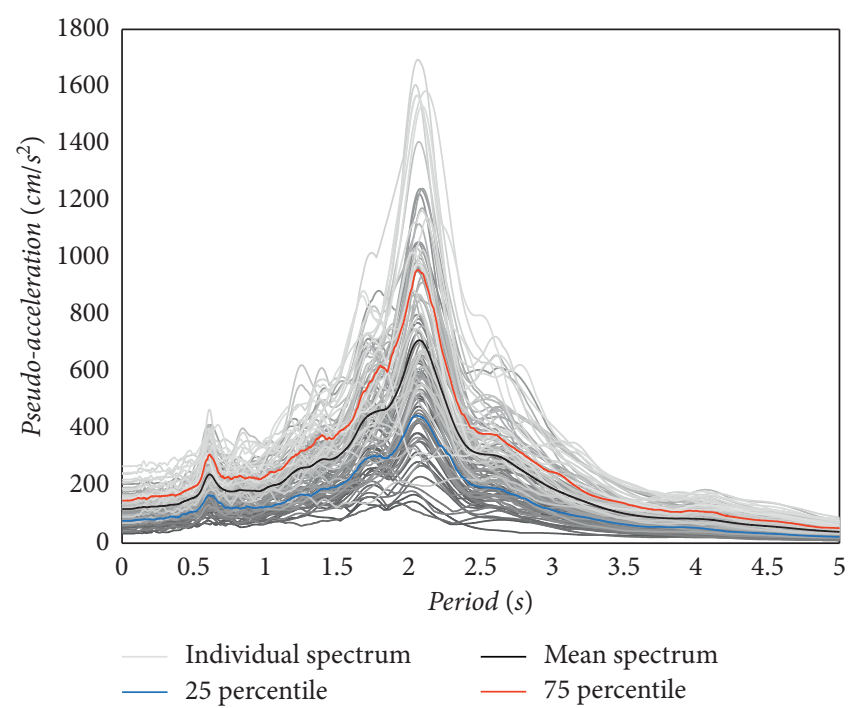

Figure 3: Seismic response spectra of all the selected simulated ground motion records including mean, and 25th and 75th percentiles.

$\mathrm{Sa}\left(\mathrm{T}_{1}\right)$ as it is illustrated in the following equation:

$$
N_{p}=\frac{S a_{\mathrm{avg}}\left(T_{1} \ldots T_{N}\right)}{\operatorname{Sa}\left(T_{1}\right)} .
$$

The information given by the $N_{p}$ equation is that if we have one or $n$ records with a mean $N_{p}$ value close to one, we can expect an average spectrum near flat in the period range between $T_{1}$ and $T_{N}$. For a mean $N_{p}$ lower than one, it is expected an average spectrum with a negative slope, and finally, $N_{p}$ values larger than one are representative of spectra with positive slope increasing the spectral ordinates.

To incorporate the influence of nonlinear behavior in the prediction of structural response, Bojórquez and Iervolino proposed a new scalar ground motion intensity measure based on $S a\left(T_{1}\right)$ and $N_{p}$, which is described by the following equation:

$$
I_{N p}=S a\left(T_{1}\right) \cdot N_{P}^{\alpha} \text {. }
$$

In (3), $I_{N p}$ is a scalar ground motion intensity measure, $S a\left(T_{1}\right)$ is the commonly known intensity measure, and $N_{p}$ is the spectral shape parameter, and the $\alpha$ value must be calibrated according to the structure and the selected seismic demand parameter. Different researchers have demonstrated the great potential of the $I_{N p}$ intensity measure $[1,6,7,43]$. For this reason, in this study, the two selected ground motion intensity measures are $S a\left(T_{1}\right)$ and $I_{N p}$ to propose new UAFR spectra based on ductility and dissipated hysteretic energy.

(4) Selection of the performance parameters (ductility and hysteretic energy)
In this work, the ductility and normalized hysteretic energy were selected as performance parameters.

Ductility

The ductility is defined as the ability of a system to be deformed without significant loss of resistance. The term ductility factor $\mu$ is defined as a measure of the amount of energy dissipation capacity as follows:

$$
\mu=\frac{u_{\max }}{u_{y}}
$$

where $u_{\max }$ is the maximum absolute displacement achieved by the system and $u_{y}$ is the yielding displacement. For this study, ductility capacity values of 2,3, and 4 have been selected according to the recommendations of the Mexican City Building Code.

Normalized hysteretic energy

Energy-based methodologies focus on providing structures with energy dissipation capacities larger than or equal to their expected energy demands $[13,14]$. The energy most related to the structural damage is the hysteretic energy $E_{H}$. The dissipated hysteretic energy can be interpreted physically by considering that it is equal to the area enclosed by each of the hysteresis loops that the structure develops during a seismic excitation. Although hysteretic energy provides an approximate idea of the accumulated plastic deformation demands, this response parameter by itself does not provide sufficient information to evaluate the structural behavior, so it is convenient to normalize it as follows:

$$
E_{N}=\frac{E_{H}}{F_{y} \delta_{y}},
$$

where $F_{y}$ and $\delta_{y}$ are the strength and displacement at first yield, respectively. $E_{N}$ is a parameter that correlates best with the structural damage $[44,45]$. In this work, the normalized hysteretic energy is considered as a parameter to control the accumulated damage. Thus, $E_{N}$ UAFR spectra are computed.

(5) Estimation of the structural response of the system by incremental dynamic analysis (IDAs) [46] for a selected period $T_{1}$ and yield force coefficient $\mathrm{Cy}$ (defined as the yielding force divided by the total weight of the system) subjected to ground motion records scaled in terms of $S a\left(T_{1}\right)$ or $I_{N p}$. The seismic responses obtained in this study are the ductility and normalized dissipated hysteretic energy as it was previously discussed.

(6) Proposing specific values of ductility capacity or normalized dissipated hysteretic energy. In this work, the ductility capacity values correspond to those indicated by the Mexico City Building Code. On the other hand, different values for the 
normalized hysteretic energy capacity are suggested in Bojórquez et al. [18]. For this reason, in this study the values of $3,6,9$, and 12 of the normalized hysteretic energy capacity have been selected, which are representative of reinforced concrete and steel buildings according to Terán and Jirsa [21] and Bojórquez et al. [18, 47].

(7) Assessment of the failure probability by dividing the number of ground motion records in which the ductility of energy demanded is larger than the capacity (step 6) between the total numbers of records used for a specific intensity level.

(8) Selection of the seismic hazard curve based on the seismic intensity measures $S a\left(T_{1}\right)$ and $I_{N p}$. For the present word, the seismic hazard curves computed by Rodríguez et al. have been used [48, 49].

(9) Numerical assessment of the annual failure rate using (1). The steps for other structural periods and Cy to obtain the structural annual failure rate curves are repeated.

(10) The UAFR spectra for a specific value are calculated for each of the parameters here studied.

Finally, Figure 4 shows a flow chart of the procedure to compute the UAFR spectra.

\section{Numerical Results}

The numerical results obtained in this work are presented in this section. It is important to say that all the UAFR spectra illustrated correspond to the spectra obtained via the 110 simulated narrowband earthquake ground motions. Notice that the selection of the seismic hazard curves based on the intensity measure $S a\left(T_{1}\right)$ and $I_{N p}$ is a very important issue to compute the UAFR spectra. The seismic hazard curves are used frequently to represent the seismic hazard of a specific site. They indicate the annual rate of exceeding a variety of intensity levels of a ground motion parameter at a site of interest (i.e., $S a\left(T_{1}\right)$ and $I_{N p}$ ). The procedure to compute a ground motion hazard curve is based on the total probability theorem [34, 35, 50-52]. As it was indicated previously, the seismic hazard curves for $S a\left(T_{1}\right)$ and $I_{N p}$ developed by Rodríguez et al. 2021 $[40,41]$ have been selected to compute the uniform annual failure rate spectra. For example, Figure 5 illustrates the seismic hazard curves for the SCT site corresponding to soft soil of Mexico City for periods ranging from 0.2 to 2 seconds and both selected intensity measures.

3.1. Influence of Ductility in the UAFR Spectra in terms of $S a(T 1)$. The ductility UAFR spectra when $S a\left(T_{1}\right)$ is used as intensity measure and for all the hysteretic models under consideration are illustrated in Figure 6. Furthermore, the UAFR spectra are compared for different ductility capacity levels. While Figure 6(a) shows the results for the elastoperfectly plastic hysteretic model, Figures 6(b)-6(d) correspond to elastoplastic with $3 \%, 5 \%$, and $10 \%$ of post-yielding stiffness, respectively.
All the spectra are associated with a UAFR $\nu_{F}=0.004$. It is observed that as the ductility increases, the required lateral resistance or seismic coefficient (Cy) decreases, especially for structures close to the soil period $(\mathrm{Ts}=2 \mathrm{~s})$. The largest differences are observed in the intervals of the structural periods ranging from 1.3 to 2 seconds. For example, in Figure 6(a), when $T=0.8$ seconds (structures with periods smaller than the soil period, which is equal to 2 s) and $\mu=2$, the Cy is equal to 0.25 , and for $\mu=4$, the Cy is equal to 0.21 , indicating a reduction of $16 \%$ when the ductility increases from 2 to 4 . On the other hand, if the structure is close to the soil period, for example, for a system with $T=1.6 \mathrm{~s}$ and $\mu=2$, the Cy is equal to 0.41 and for $\mu=4$ the Cy is equal to 0.24 . Thus, a reduction of $41.4 \%$ is obtained if the ductility capacity increases. Therefore, the structures with vibration period close to the soil period require special attention; in particular, this type of building is more sensitive to the ductility capacity. Similar results are observed for the elastoplastic models with different post-yielding stiffness analyzed in this study as observed in Figures 6(b)-6(d).

\subsection{Influence of Post-Yielding Stiffness in the UAFR Spectra} in terms of $\mathrm{Sa}$ Intensity Measure. The influence of postyielding stiffness is obtained by comparison of the elastoperfectly plastic and elastoplastic model with 3\% (BL03), $5 \%$ (BL05), and 15\% (BL15) of post-yielding stiffness. Figures 7 and 8 compare the UAFR spectra with $\nu_{F}=$ 0.004 and $\nu_{F}=0.008$ for two different ductility capacities $(\mu=2$ and $\mu=4)$. The selected ductility values are representative of structures with low and high levels of ductility capacity. It is observed that in both cases, the spectra are similar for all the post-yielding stiffness; therefore, it can be concluded that the post-yielding stiffness has low influence to compute the UAFR spectra, except in the case of structures with period near or about the soil period. For these cases, it is observed that as the post-yielding stiffness increases the seismic coefficient (Cy) decreases in low ratio for structures with moderately low ductility capacity $(\mu=2)$ (see Figures $7(\mathrm{a})$ and $8(\mathrm{a})$ ). On the other hand, it is shown that for structures with high ductility $(\mu=4)$ (see Figures $7(\mathrm{~b})$ and $8(\mathrm{~b})$ ), the effect of post-yielding stiffness in all the analyzed models is more evident. However, the elasto-perfectly plastic hysteretic behavior model provides reasonable results to estimate the required lateral strength in comparison with the elastoplastic model with different post-yielding stiffness.

3.3. Effect of the Annual Failure Rate $\left(\nu_{\mathrm{F}}\right)$ in the Spectra in terms of Sa Intensity Measure. In this section, the influence of the annual failure rate in the UAFR spectra is studied. For this aim, three failure rates are selected: $\nu_{\mathrm{F}}=0.008, \nu_{\mathrm{F}}=0.00$, and $\nu_{\mathrm{F}}=0.0025$, respectively. Figure 9 illustrates for a ductility value equal to 2 and the elasto-perfectly plastic hysteretic model the effect to compute spectra for the selected annual failure rates. It is observed that as the annual failure rate decreases, the seismic coefficient tends to increase, especially for 


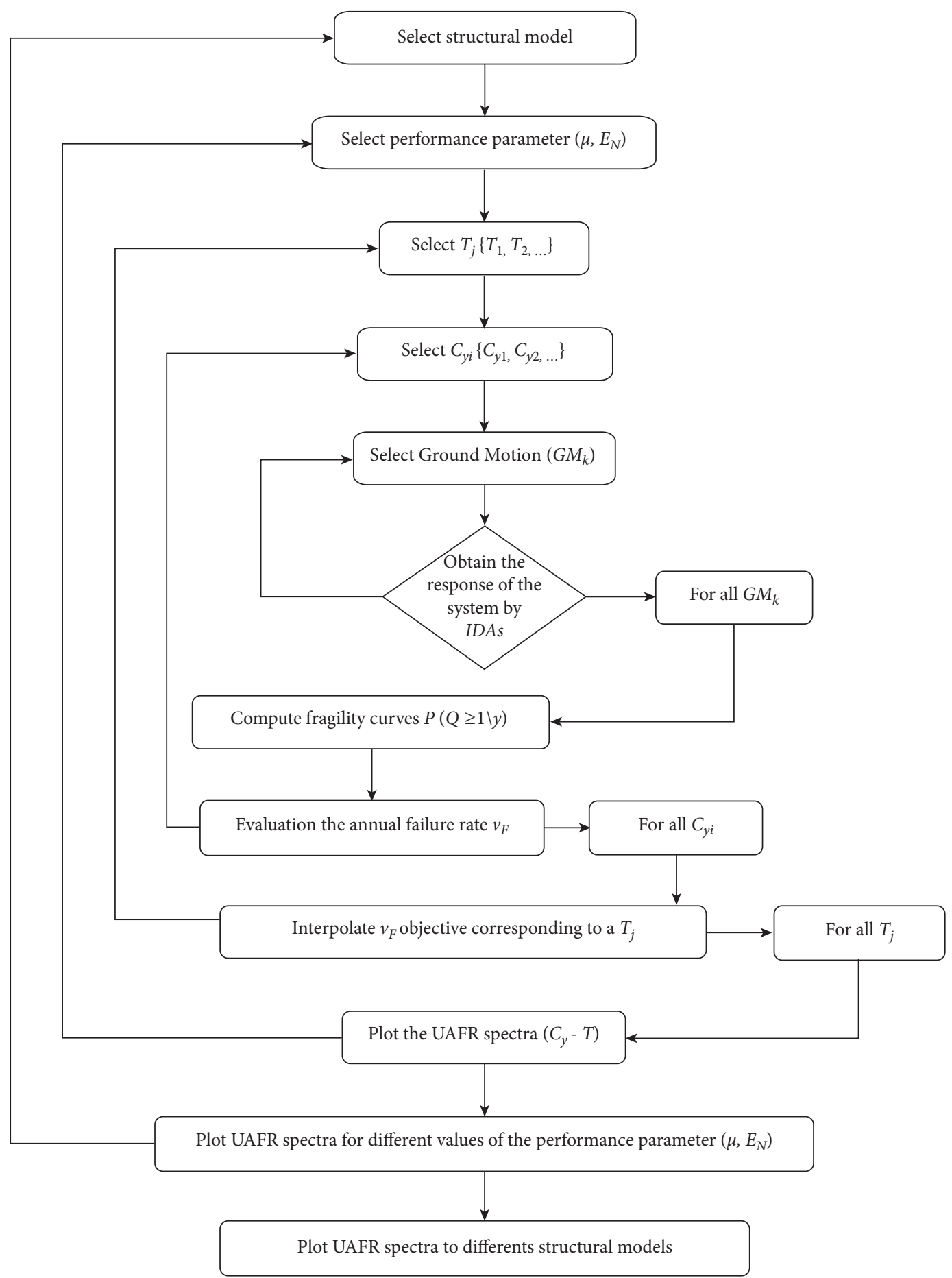

Figure 4: Flow chart of the procedure to compute the UAFR spectra.

structural periods smaller or equal to the soil period. For this reason, if the designed buildings require larger structural reliability levels, it is required to increase the lateral resistance. For example, when $T=1.0$ seconds with $v_{F}=0.008$, Cy is equal to 0.20 ; on the other hand, if $\nu_{F}=0.0025, \mathrm{Cy}=0.33$. Therefore, Cy increases about $65 \%$, while for a $T=3.0$ seconds with $\nu_{F}=0.008$, Cy is equal to 0.09 and for $\nu_{F}=0.0025$ the $\mathrm{Cy}=0.13$, and for this case, the percentage is $44.4 \%$ larger. In conclusion, it is observed that for structural periods larger or very larger than the soil period, the influence of the uniform annual failure rate selected to compute Cy tends to be despicable.

3.4. Influence of the Hysteretic Energy in the UAFR Spectra in terms of the Sa Intensity Measure. The normalized hysteretic energy UAFR spectra when $S a$ is used as intensity measure for all the models with different post-yielding stiffness under 


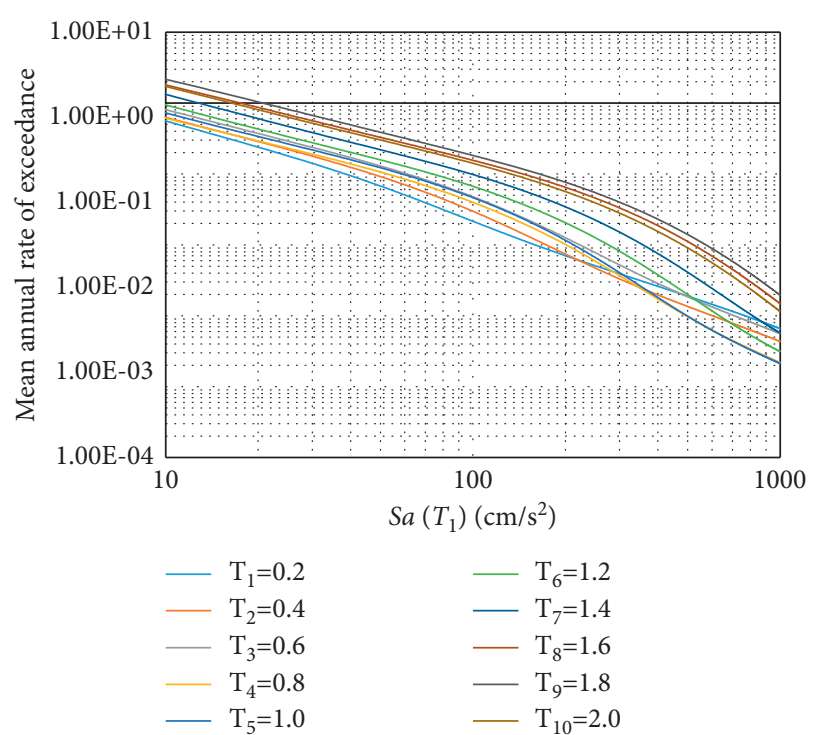

(a)
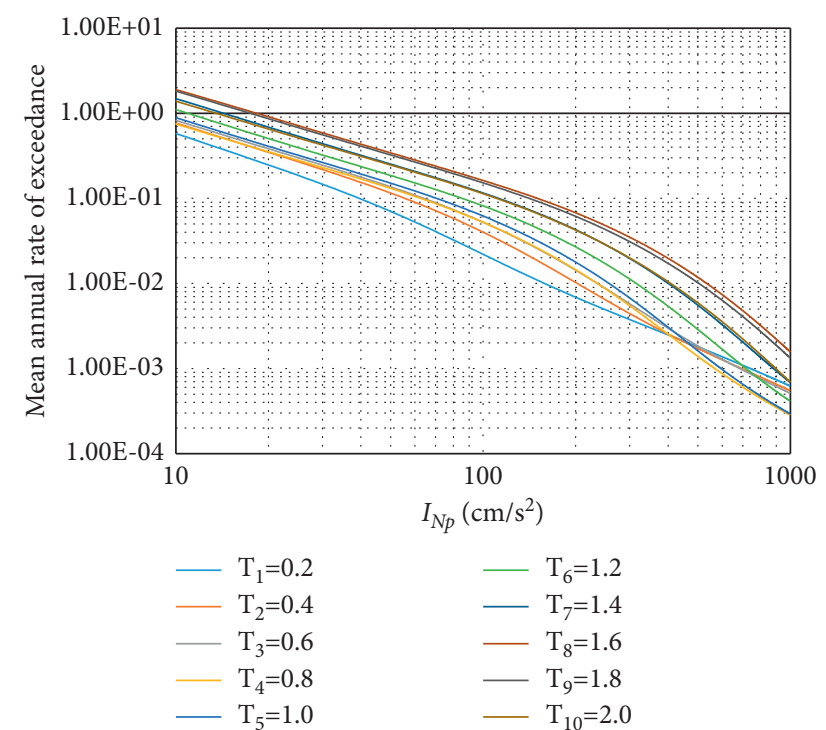

(b)

FIGURE 5: Example of the selected seismic hazard curves for (a) $S a\left(T_{1}\right)$ and (b) $I_{N p}$.

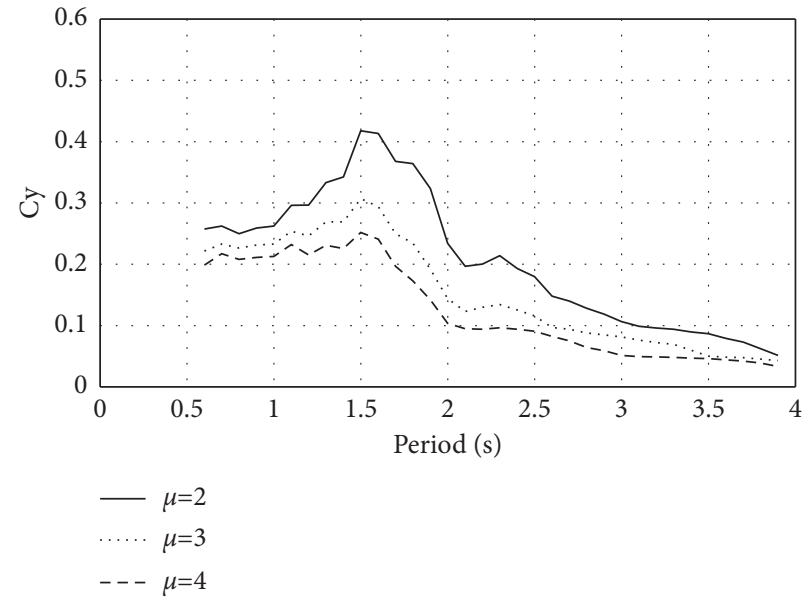

(a)

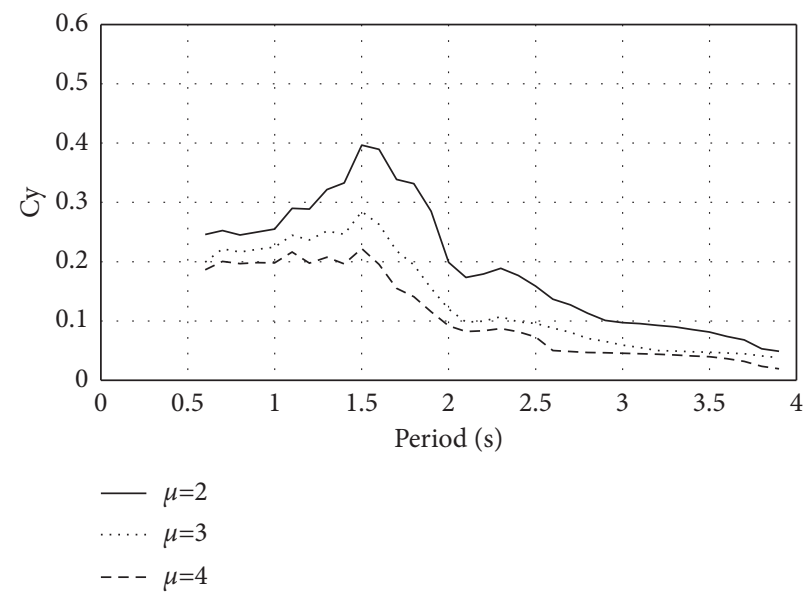

(c)

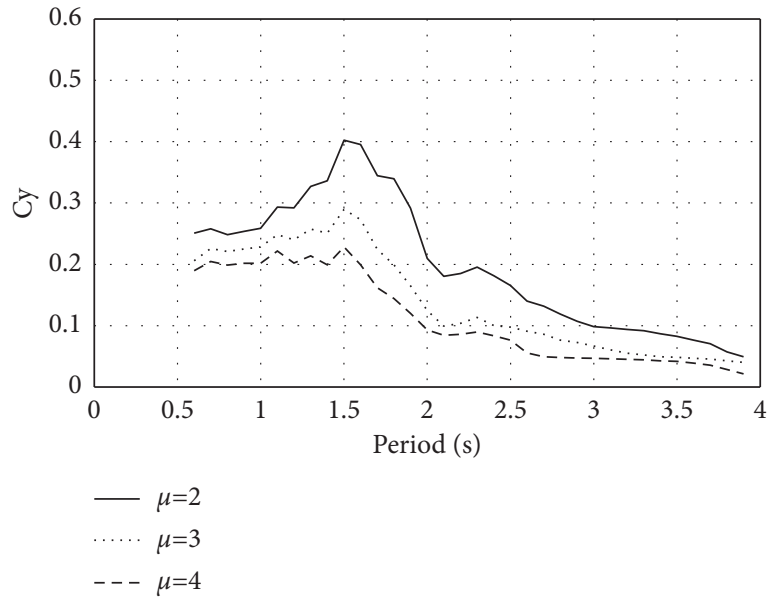

(b)

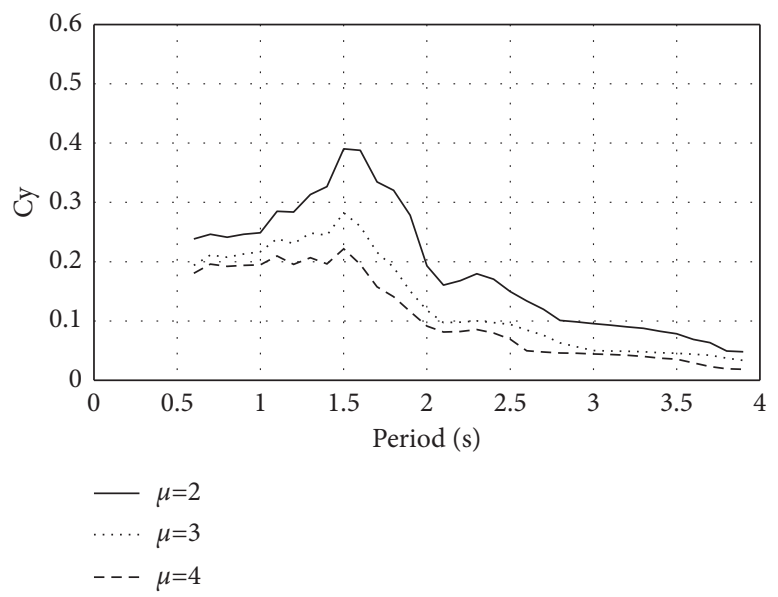

(d)

FIGURE 6: Ductility UAFR spectra for $\nu_{F}=0.004$ and the nonlinear hysteretic models: (a) elasto-perfectly plastic and elastoplastic with (b) $3 \%$, (c) $5 \%$, and (d) $10 \%$ of post-yielding stiffness. 


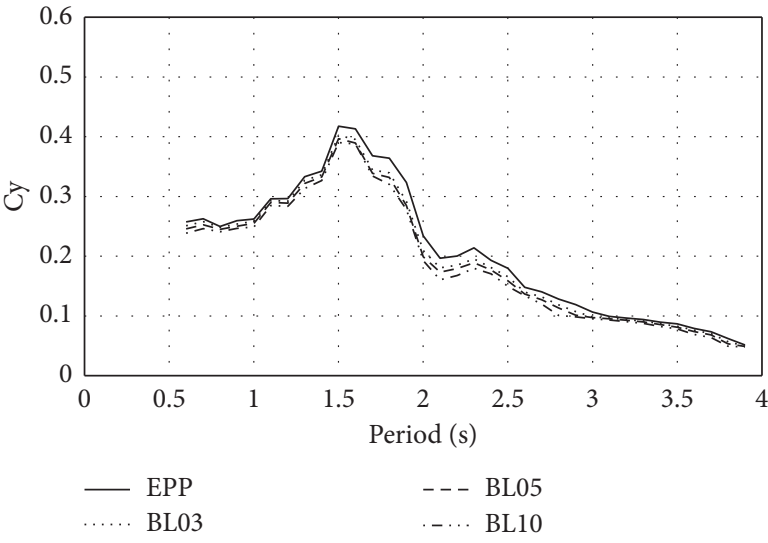

(a)

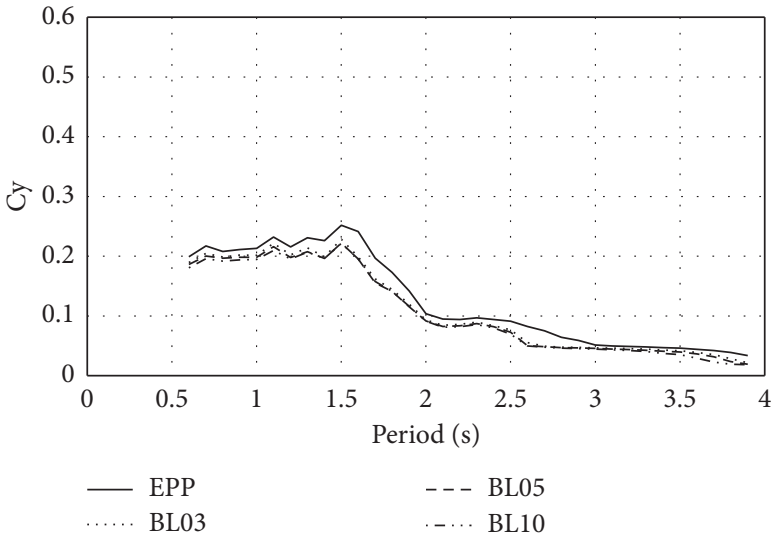

(b)

Figure 7: Ductility UAFR spectra with $v_{F}=0.004$ (250 years of return period) and different levels of post-yielding stiffness. (a) Spectrum for $\mu=2$. (b) Spectrum for $\mu=4$.

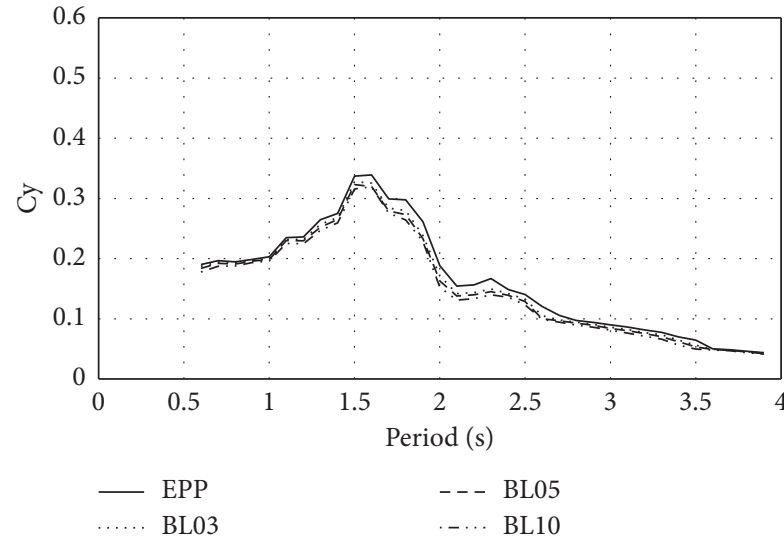

(a)

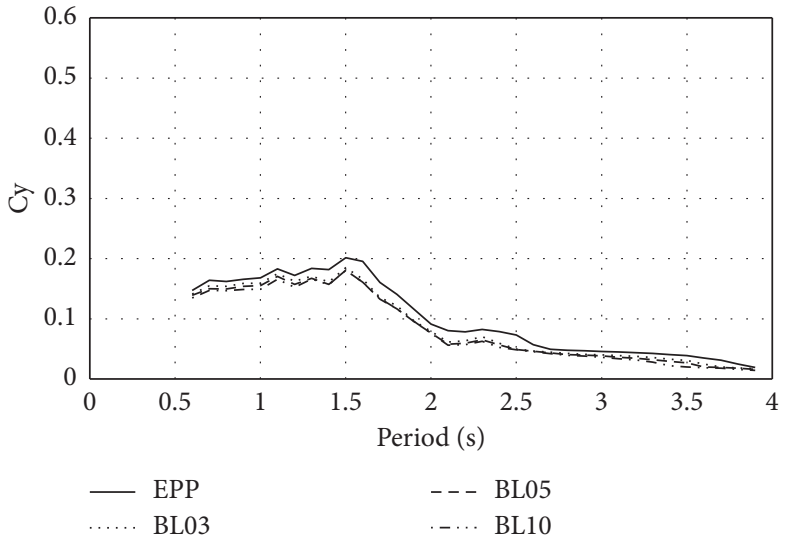

(b)

FIGURE 8: Ductility UAFR spectra with $\nu_{F}=0.008$ and different levels of post-yielding stiffness. (a) Spectrum for $\mu=2$. (b) Spectrum for $\mu=4$.

consideration are illustrated in Figure 10. The UAFR spectra are compared for different levels of energy capacity for the nonlinear models. Figure 10(a) shows the results for the elasto-perfectly plastic model and Figures 10(b)-10(d) for $3 \%, 5 \%$, and $10 \%$ of post-yielding stiffness. Notice that all the spectra are associated with a UAFR $\nu_{F}=0.004$. It is observed that as the energy increases, the required lateral resistance decreases, particularly in the region of periods close to the soil period. The same trend is observed for the different postyielding stiffness selected in this study.

The influence of post-yielding stiffness on the behavior models in the UAFR spectra is compared in Figures 11 and 12 , with $v_{F}=0.004$ and $\nu_{F}=0.008$. It is very interesting to observe that the figures suggest that the UAFR spectra are similar for the different post-yielding stiffness. This conclusion is also valid if the energy capacity selected or annual failure rate is different.

3.5. Effect of Failure Rates in Hysteretic Energy UAFR Spectra in terms of Sa Intensity Measure. In this section, the influence of the annual failure rate in the UAFR spectra in terms of the dissipated hysteretic energy capacity is studied. For this aim, three failure rates are selected: $\nu_{\mathrm{F}}=0.008, \nu_{\mathrm{F}}=$ 0.004 , and $\nu_{\mathrm{F}}=0.0025$ respectively; see Figure 13 . It is observed that as the failure rates decrease, the required lateral resistance increases. Similar results were found for all the periods under consideration. It is important to say that similar results were obtained when comparing the UAFR spectra in terms of $I_{N p}$ as intensity measure with respect to the previously mentioned parameters. The following section compares the results obtained for $S a$ and $I_{N p}$ intensity measures.

\section{Comparison of Ductility UAFR Spectra: $S a$ vs. $I_{N p}$}

In this part, the results of ductility UAFR spectra for the previously mentioned intensity measures are compared. In Figures 14 and 15, the elasto-perfectly plastic behavior for different ductility values with annual failure rates equal to 0.004 and 0.008 is used to compare the UAFR spectra. Figure 14(a) shows the UAFR spectra for a ductility value equal to 2 . It is observed that the lateral resistance required 


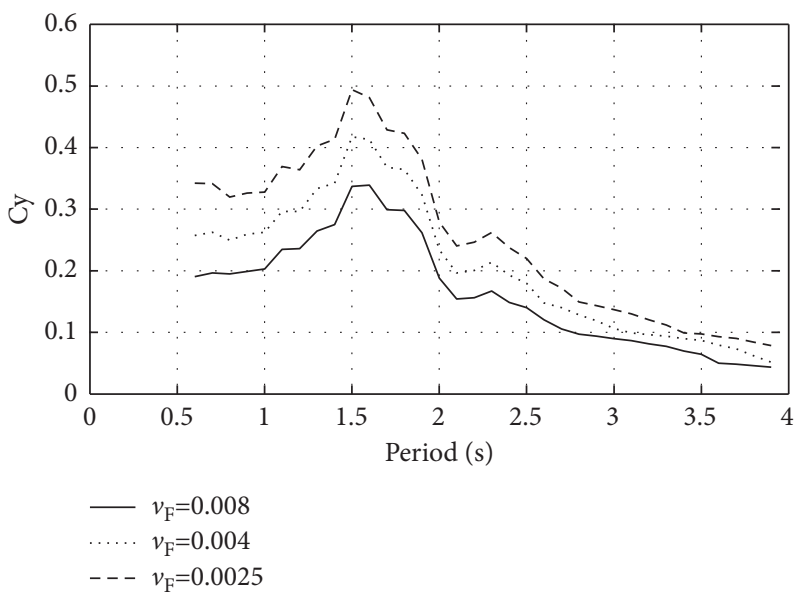

FIgURE 9: Ductility UAFR spectra for elasto-perfectly plastic model and $\mu=2$ and three different annual failure rates $\left(v_{F}=0.0025, v_{F}=0.004\right.$, and $\left.v_{F}=0.008\right)$.

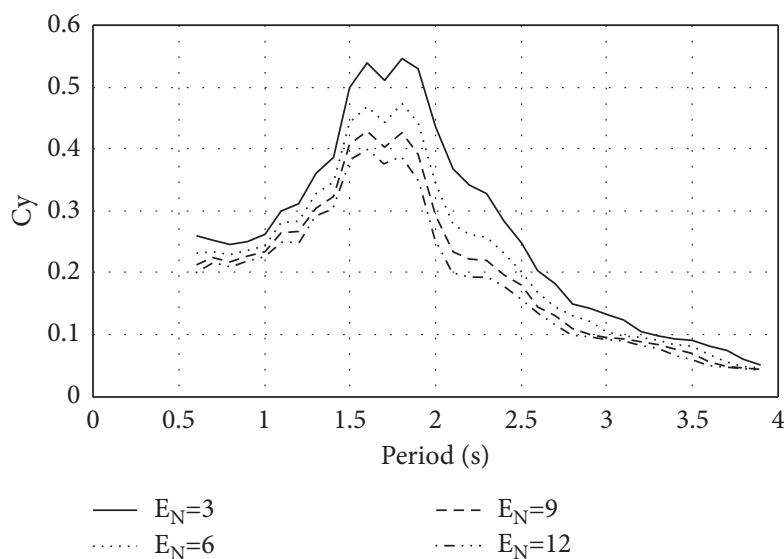

(a)

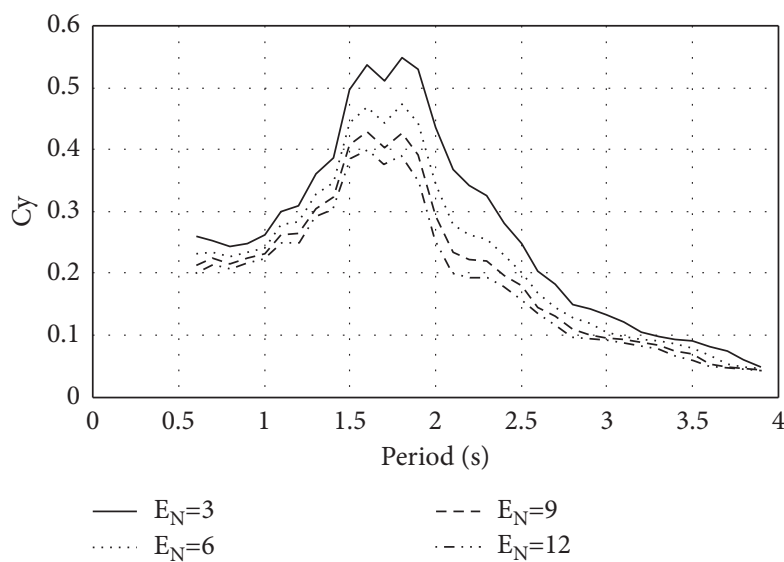

(c)

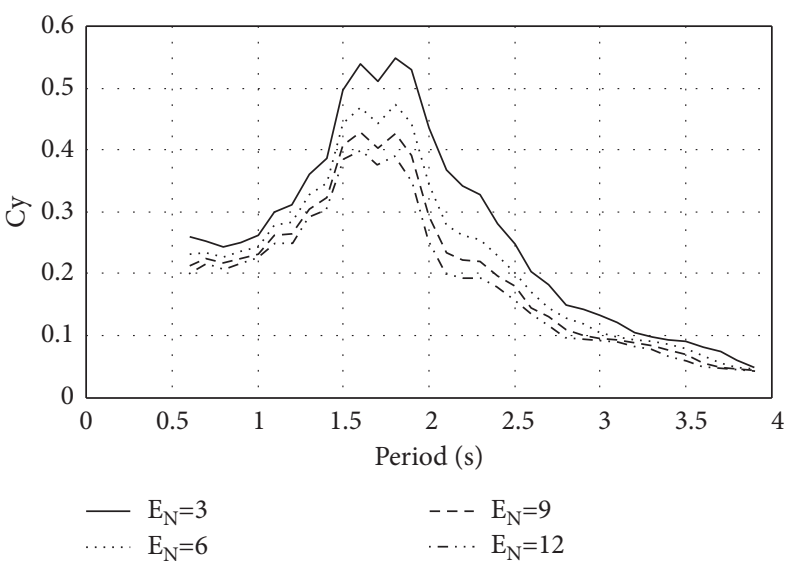

(b)

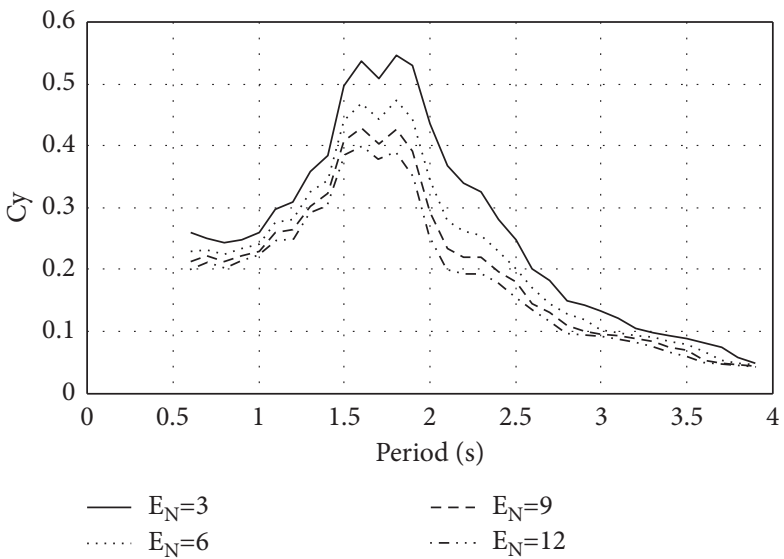

(d)

FIGURE 10: Normalized hysteretic energy UAFR spectra with $v_{F}=0.004$ for the nonlinear models: (a) elasto-perfectly plastic and elastoplastic with (b) $3 \%$, (c) $5 \%$, and (d) $10 \%$ of post-yielding stiffness.

for both intensity parameters is similar for periods less than 1.6 seconds, while for periods between the ranges of 1.6 and 2.5 seconds a significant difference is observed when using both intensity measures selected to compute the lateral resistance required. For example, from Figure 14(a) and a period equal to 1.3 seconds, the values of $\mathrm{Cy}=0.31$ for $I_{N p}$ and $\mathrm{Cy}=0.33$ for $\mathrm{Sa}$ have a difference of $6 \%$, and for a period equal to 2.0 seconds, a $\mathrm{Cy}=0.23$ is obtained for $\mathrm{S} a$ and 

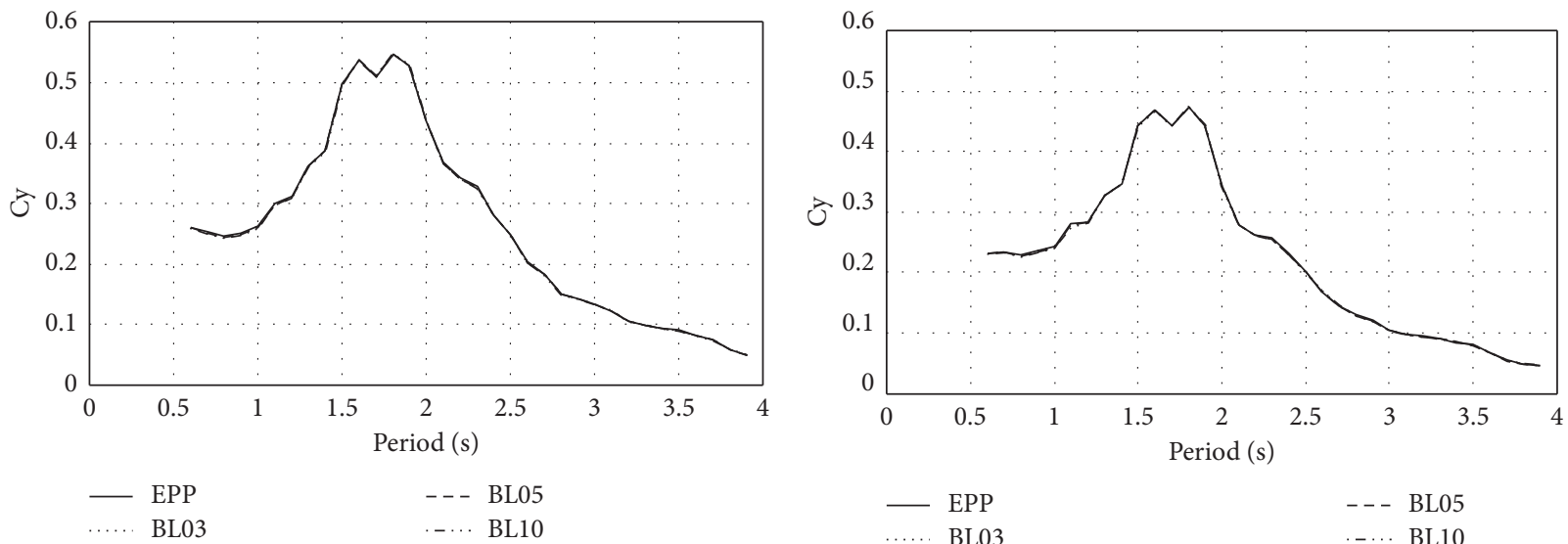

EPP
BL... 03

--- BL05

(a)

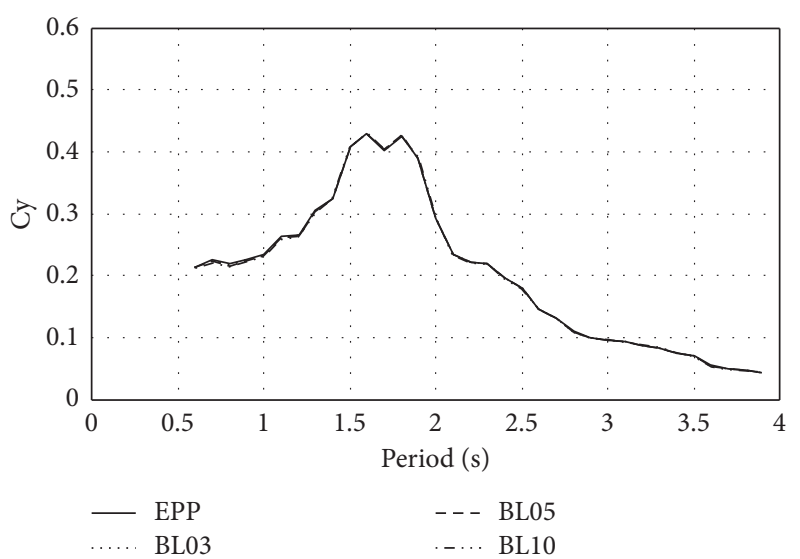

(c)

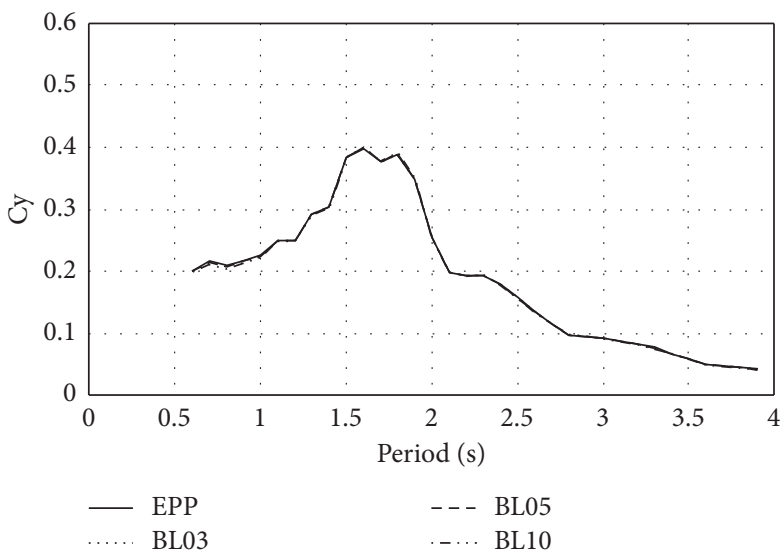

(d)

FIGURE 11: Normalized hysteretic energy UAFR spectra with $\nu_{F}=0.004$ and different levels of post-yielding stiffness for (a) $E_{N}=3$, (b) $E_{N}=6,(\mathrm{c}) E_{N}=9$, and (d) $E_{N}=12$.

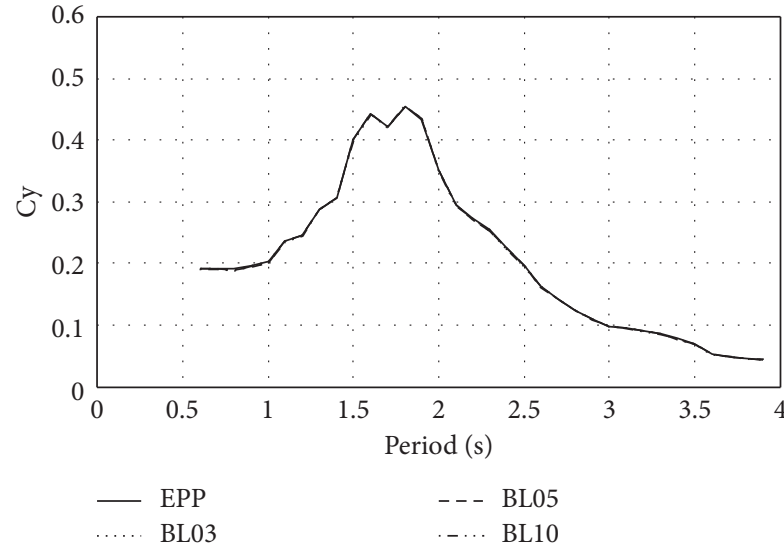

(a)

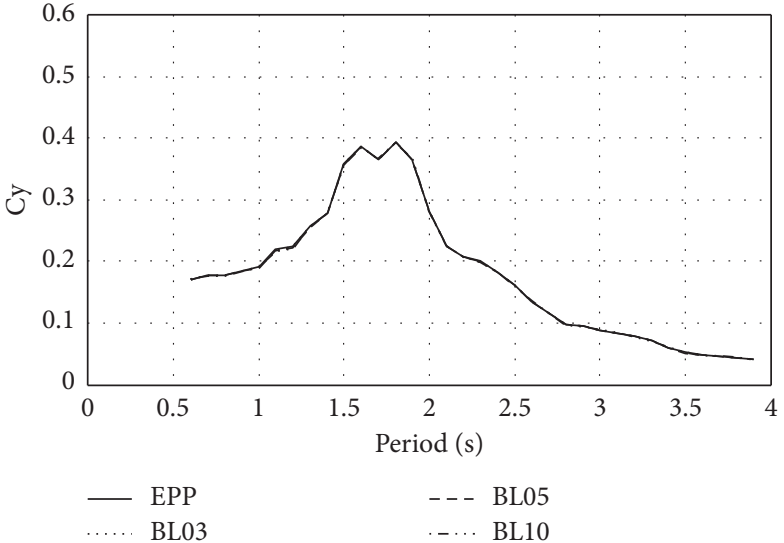

(b)

Figure 12: Continued. 


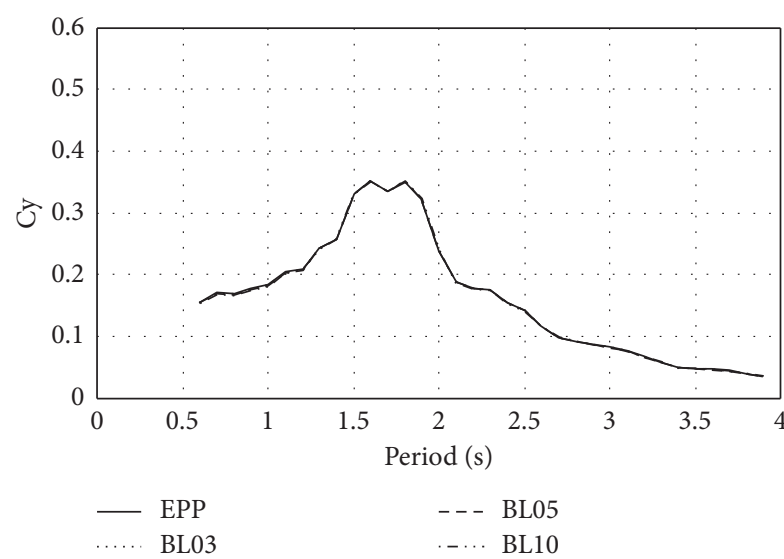

(c)

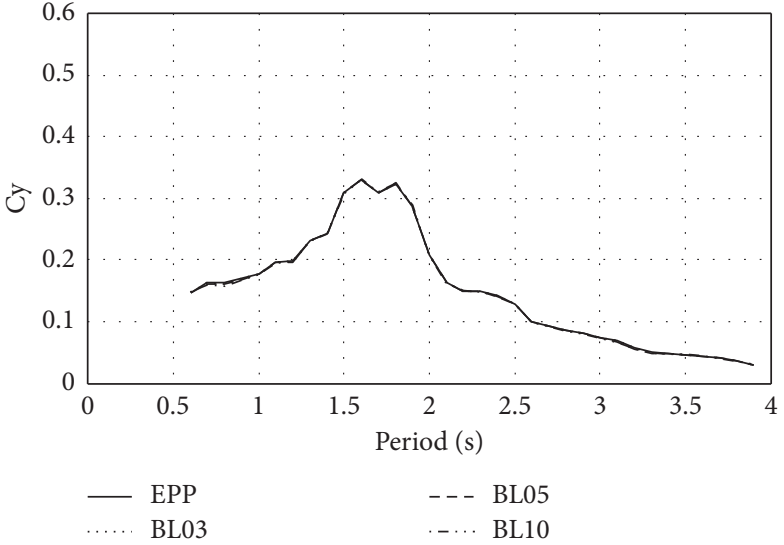

(d)

Figure 12: Normalized hysteretic energy UAFR spectra with $v_{F}=0.008$ and different levels of post-yielding stiffness for (a) $E_{N}=3$, (b) $E_{N}=6$, (c) $E_{N}=9$, and (d) $E_{N}=12$.

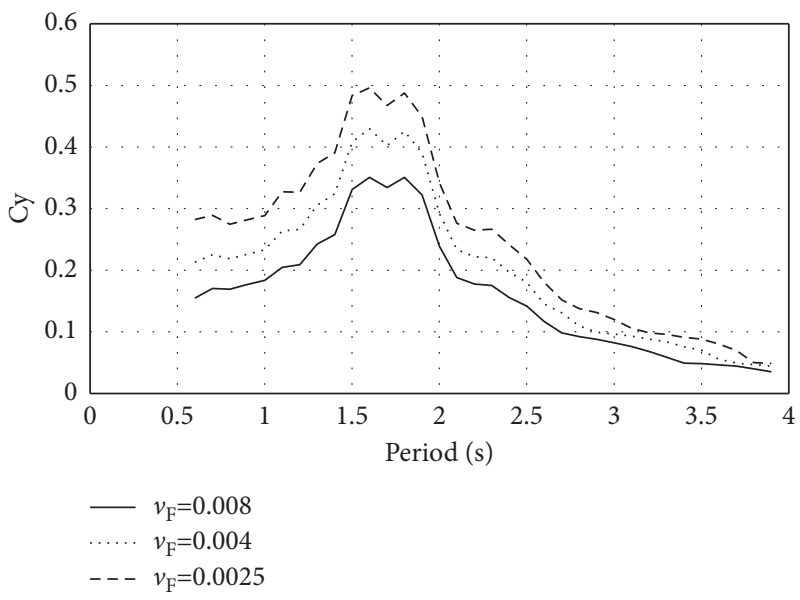

FIgURE 13: Comparison of normalized hysteretic energy UAFR spectra with $E_{N}=9$ for the elasto-perfectly plastic hysteretic model and different annual failure rates.

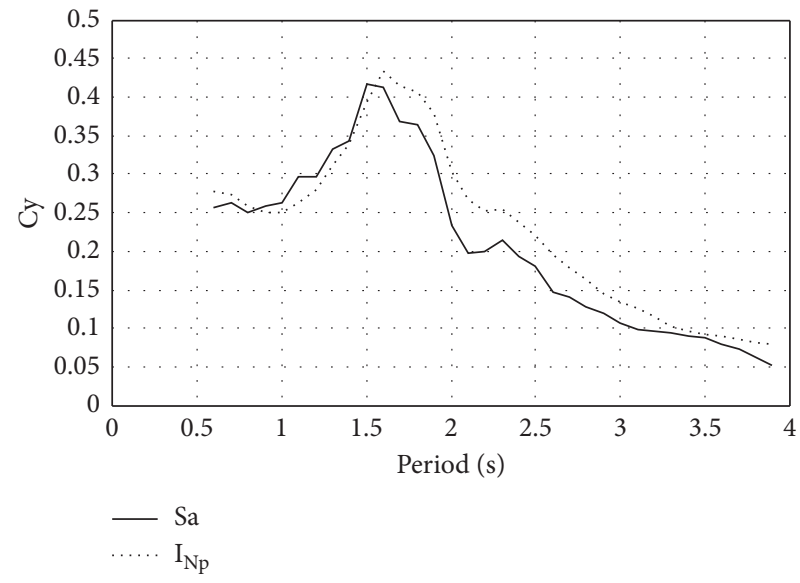

(a)

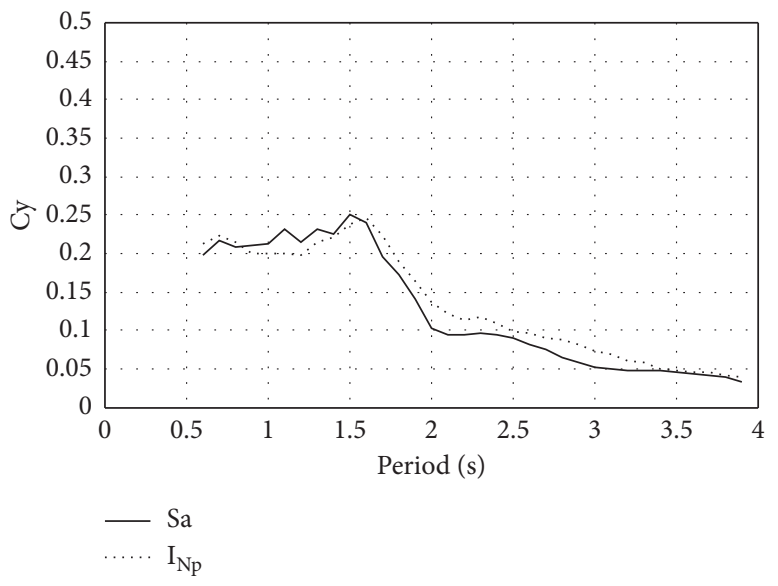

(b)

FIGURE 14: Ductility UAFR spectra for the elasto-perfectly plastic hysteretic model with annual failure rate equal to 0.004 and two different ductility values. (a) Spectrum for $\mu=2$. (b) Spectrum for $\mu=4$. 

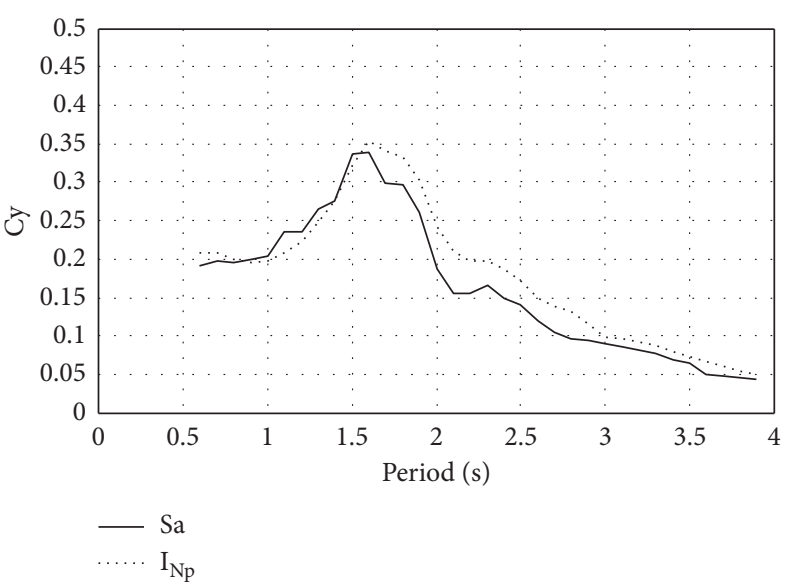

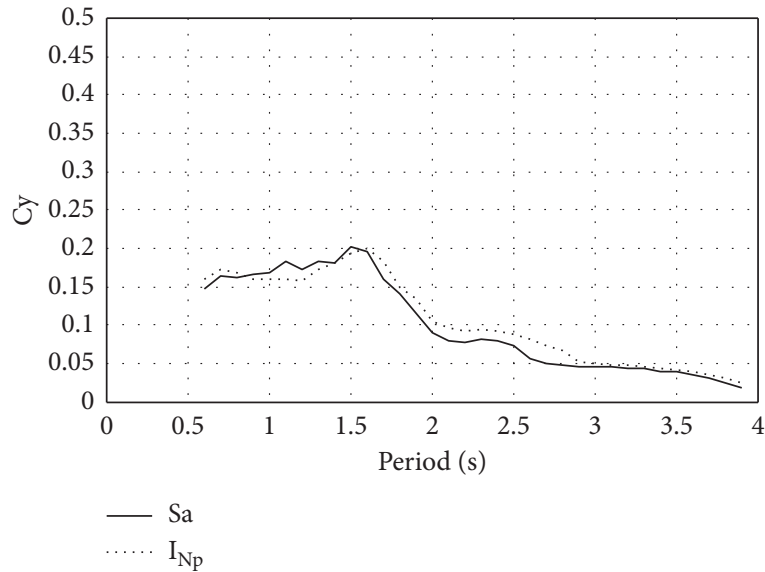

(b)

Figure 15: Ductility UAFR spectra for the elasto-perfectly plastic hysteretic model with annual failure rate equal to 0.008 and two different ductility values. (a) Spectrum for $\mu=2$. (b) Spectrum for $\mu=4$.

Cy $=0.30$ for $I_{N p}$, and this difference represents about $30 \%$. On the other hand, Figure 14(b) shows the UAFR spectra for ductility equal to 4 , where both intensity measures are compared. The results suggest that the value of $\mathrm{Cy}$ is very similar for all the periods of the systems under consideration.

The effect of the influence of the ductility value is compared in Figures 14(a) and 14(b). It is found that as the ductility increases, the required lateral resistance decreases considerably for all periods of the systems analyzed in this study, varying from $30 \%$ to $60 \%$ as the ductility value increases from $\mu=2$ to $\mu=4$, respectively. Similar results are found in Figures 15(a) and 15(b) for annual failure rate equal to 0.008 . In general, the results suggest that for structures with low ductility capacity such as masonry or reinforced concrete buildings, the selection of an appropriate intensity measure is very important in the case of ductility UAFR spectra at least when several ground motion records are used to compute the average spectrum. It is important to say that the authors will study in future works the importance of efficient intensity measures and the number of records used for nonlinear dynamic analysis to compute the UAFR spectra.

Figures 16 and 17 show the UAFR spectra for ductility values 2 and 4 , respectively, where the influence of failure rates $\left(\nu_{F}=0.004\right.$ and $\left.\nu_{F}=0.008\right)$ also is compared. It is observed that as the values of the annual failure rate decrease, the required lateral resistance increases up to $30 \%$ for structural periods less or equal to the soil period, and the increment is up to $20 \%$ higher for periods larger than the soil period. This observation applies for both ground motion intensity measures studied in this work (see Figures 16 and 17).

\section{Comparison of Normalized Hysteretic Energy UAFR Spectra: $S a$ vs. $I_{N p}$}

The normalized hysteretic energy UAFR spectra are compared in Figures 18 and 19 for the intensity measures $S a$ and $I_{N p}$ and the elasto-perfectly plastic behavior model with one annual failure rate and different levels of energy capacities. Figures 18(a) and 18(b) show the UAFR spectra associated with annual failure rate equal to 0.004. A similar effect is observed for both intensity measures for the structures with periods less than 1.5 seconds. However, for structural periods between 1.6 and 2.3 seconds (particularly in the region of periods close to the soil period), an important effect is found when using $S a$ or $I_{N p}$, where the seismic coefficient Cy increases more in the case of $I_{N p}$ compared with $\mathrm{Sa}$. This conclusion is valid for the annual failure rate equal to 0.004 and 0.008 (see Figures 18 and 19).

The following figures (Figures 20 and 21) compare the influence of the annual failure rate at different normalized hysteretic energy values. Figures 20 and 21 show the UAFR spectra for $E_{N}$ equal to 6 and 9, respectively, where the influence of failure rates $\left(v_{F}=0.004\right.$ and $\left.\nu_{F}=0.008\right)$ is compared. The figures illustrate that as the values of $\nu_{F}$ decrease, the required lateral resistance increases up to $20 \%$ for structural periods close to the soil period. Finally, because $I_{N p}$ is a more efficient intensity measure in comparison with the most used intensity measure $\mathrm{Sa}\left(T_{1}\right)$, the results indicate that in the case of cumulative demands such as hysteretic energy, the lateral resistance required is larger when an appropriate intensity measure such as $I_{N p}$ is selected. In fact, for example for a structural period equal to 2 (the soil period), the seismic coefficient could be up to 34\% larger when using $I_{N p}$ instead of $S a$. Thus, the use of the intensity measure $S a\left(T_{1}\right)$ could provide a lateral resistance that produces unsafety structural designs accounting for cumulative plastic deformation demands. In other words, for energy-based design or energy-based spectra it is concluded that $I_{N p}$ should be used as intensity measure. Finally, Figure 22 compares the ratio of the seismic coefficient obtained for the normalized hysteretic energy UAFR spectra in terms of $I_{N p}$ divided by that obtained via the spectral acceleration in the case of the elasto-perfectly plastic model with annual failure rate equal to 0.004 and different values of $E_{N}$. This figure confirms that the seismic coefficient could be as larger as $45 \%$ when using $I_{N p}$ in comparison with $\mathrm{Sa}\left(\mathrm{T}_{1}\right)$. 


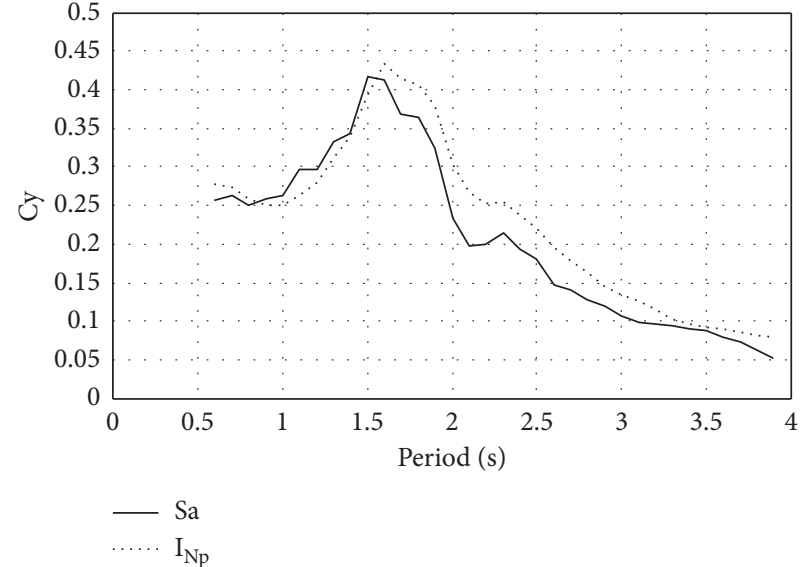

(a)

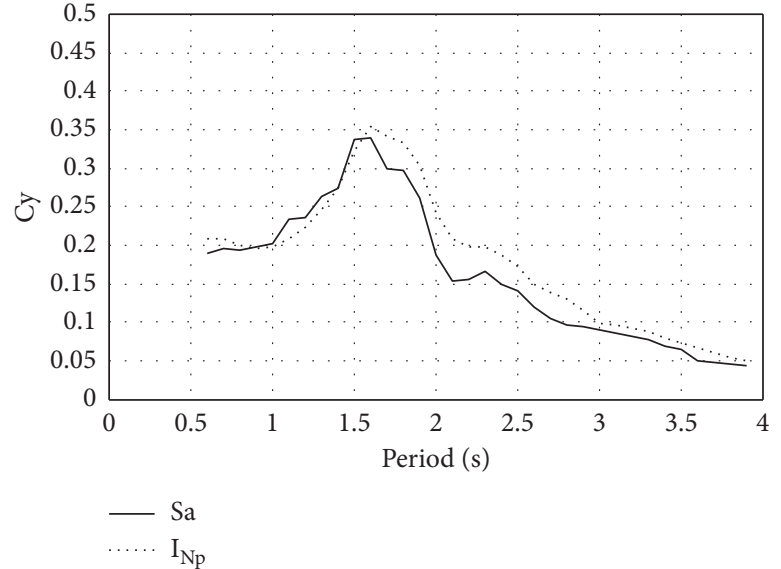

(b)

FIGURE 16: Ductility UAFR spectra for the elasto-perfectly plastic hysteretic model with $\mu=2$. (a) Spectrum for $\nu_{F}=0.004$. (b) Spectrum for $v_{F}=0.008$.

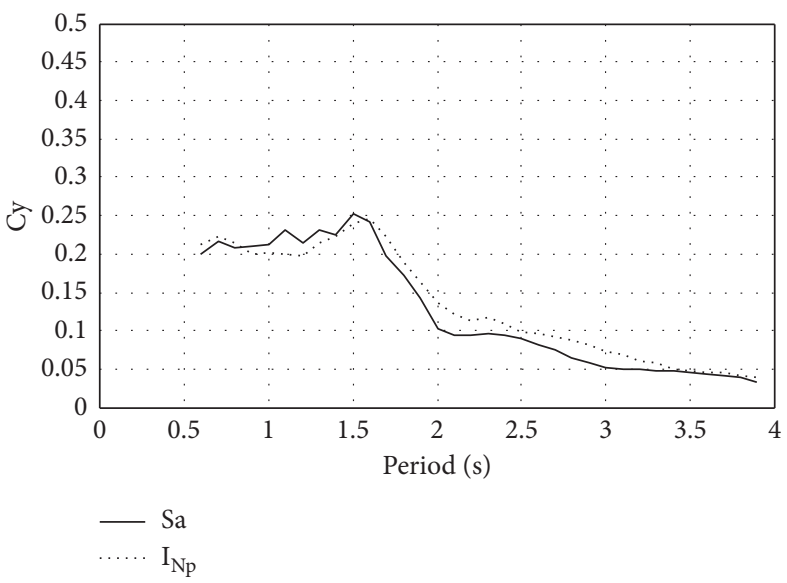

(a)

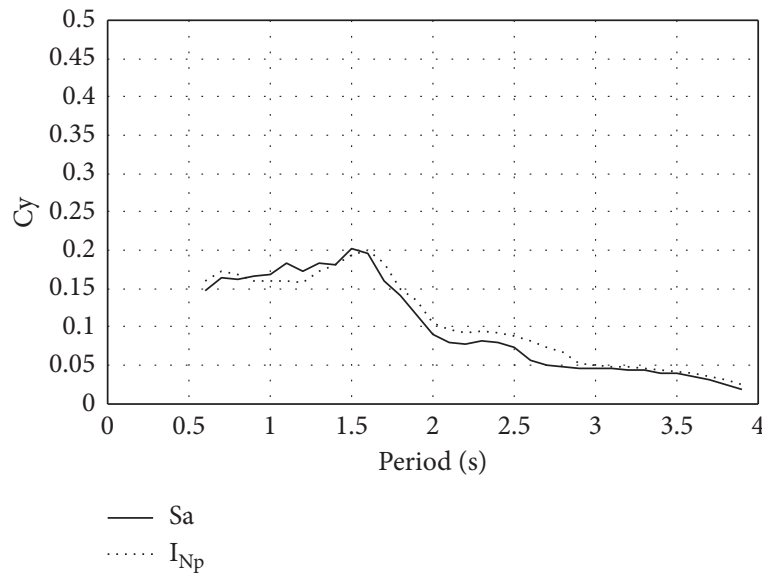

(b)

FIGURE 17: Ductility UAFR spectra for the elasto-perfectly plastic hysteretic model with $\mu=4$. (a) Spectrum for $\nu_{F}=0.004$. (b) Spectrum for $v_{F}=0.008$.

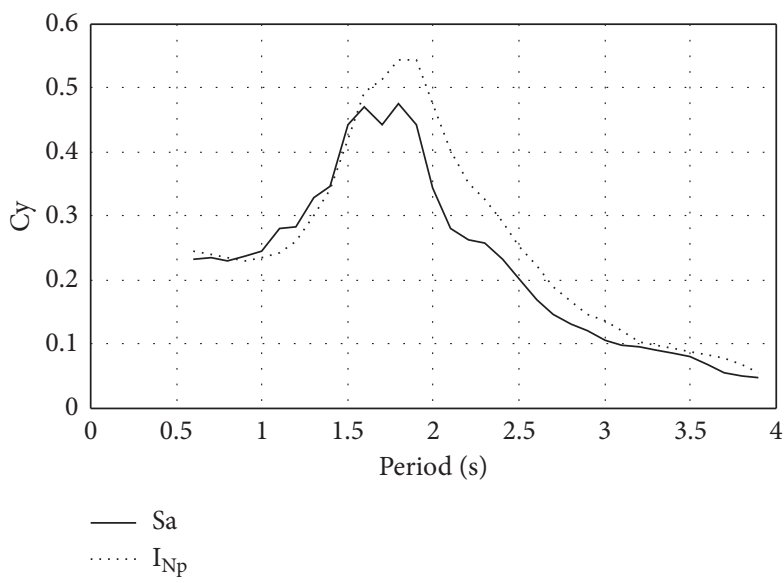

(a)

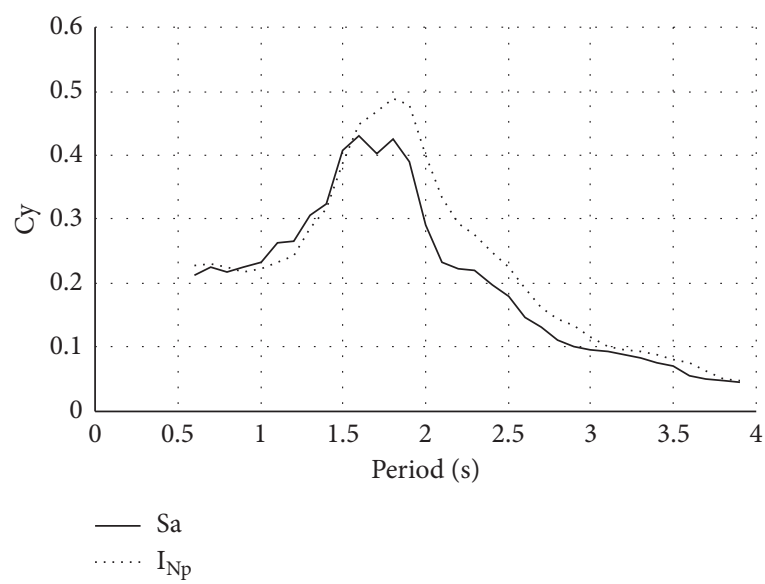

(b)

FIGURE 18: Normalized hysteretic energy UAFR spectra for the elasto-perfectly plastic model with annual failure rate equal to 0.004 and two values of $E_{N}$. (a) Spectrum for $E_{N}=6$. (b) Spectrum for $E_{N}=9$. 


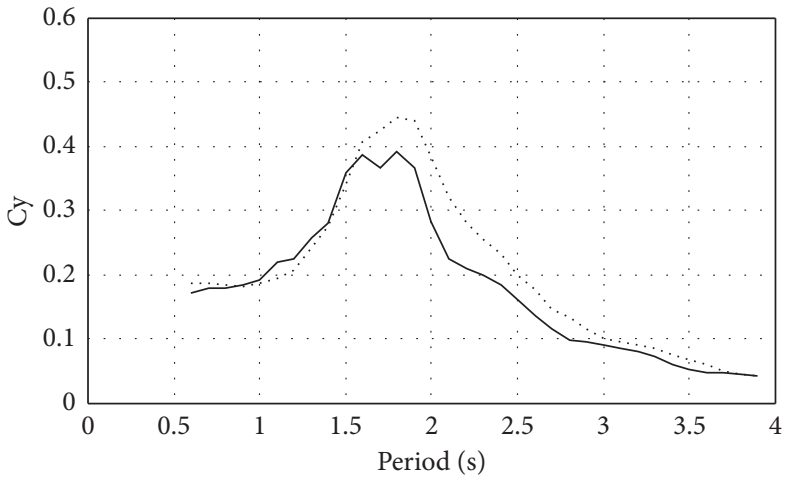

$\begin{array}{ll}-\mathrm{Sa} \\ \ldots . . . & \mathrm{I}_{\mathrm{Np}}\end{array}$

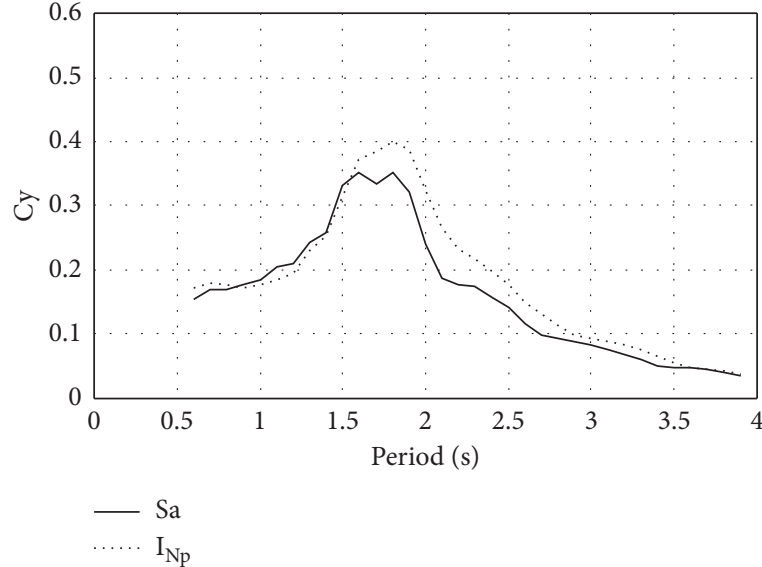

(b)

FIGURE 19: Normalized hysteretic energy UAFR spectra for the elasto-perfectly plastic model with annual failure rate equal to 0.008 and two values of $E_{N}$. (a) Spectrum for $E_{N}=6$. (b) Spectrum for $E_{N}=9$.

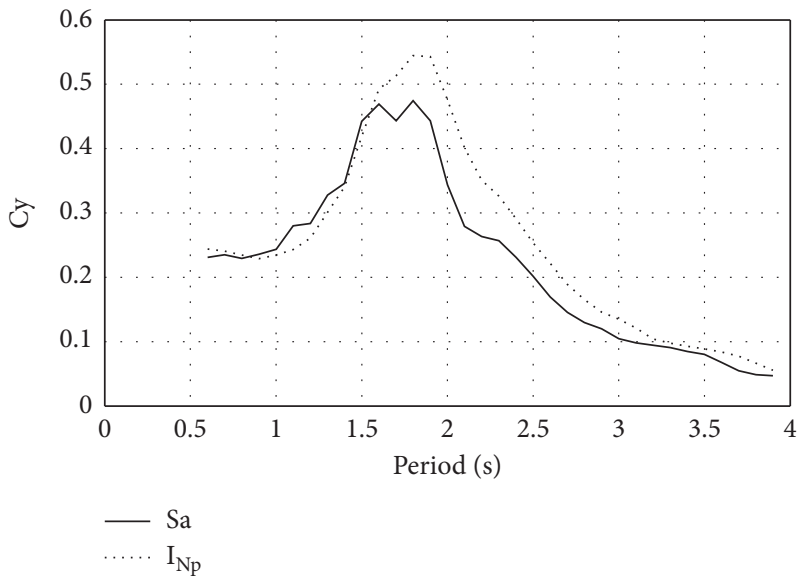

(a)

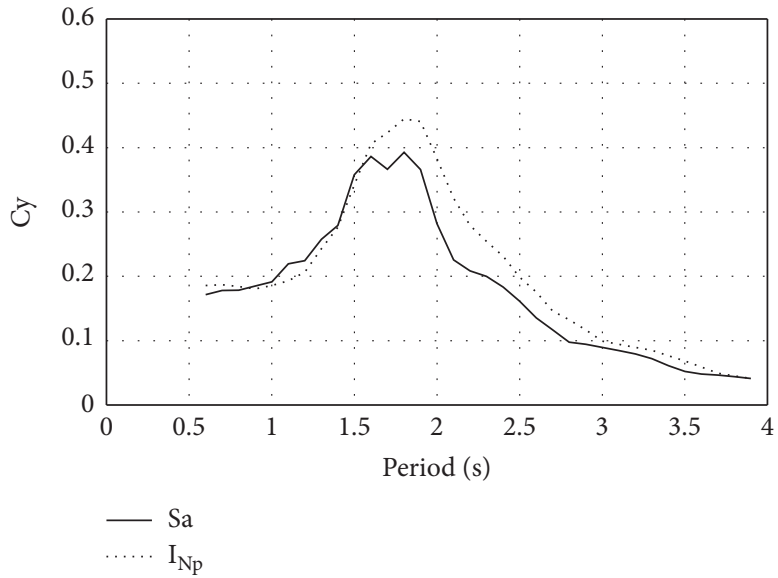

(b)

FIGURE 20: Normalized hysteretic energy UAFR spectra for the elasto-perfectly plastic model with $E_{N}=6$. (a) Spectrum for $\nu_{F}=0.004$. (b) Spectrum for $\nu_{F}=0.008$.

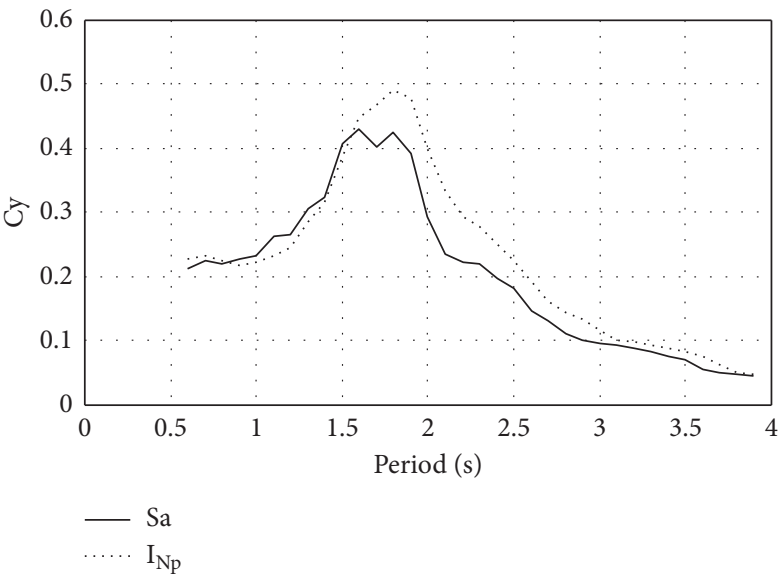

(a)

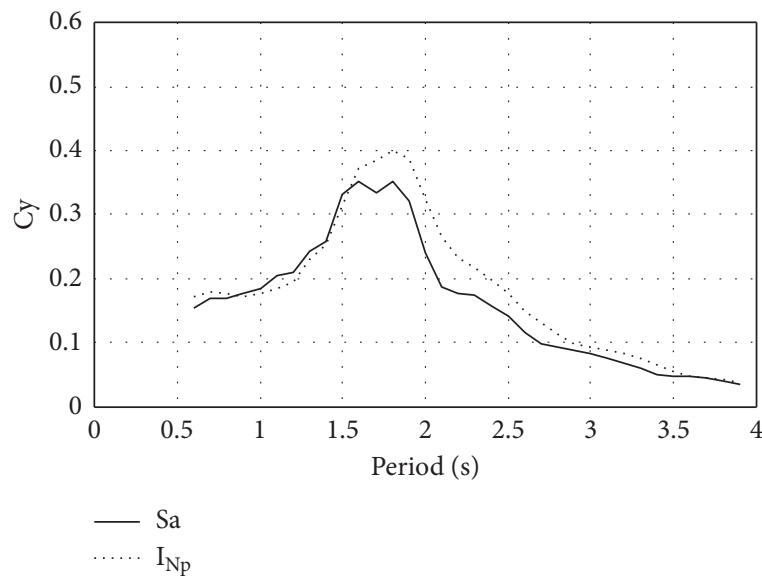

(b)

FIGURE 21: Normalized hysteretic energy UAFR spectra for the elasto-perfectly plastic model with $E_{N}=9$. (a) Spectrum for $\nu_{F}=0.004$. (b) Spectrum for $\nu_{F}=0.008$. 


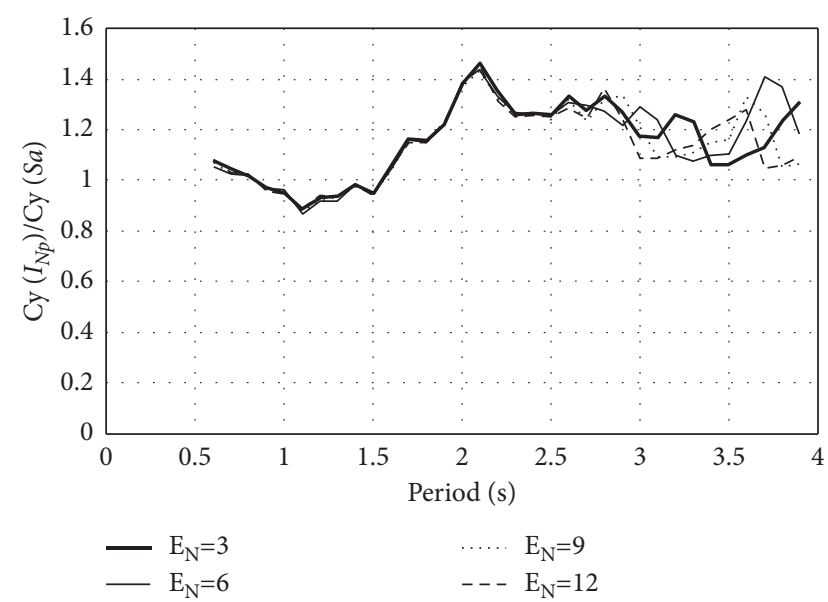

Figure 22: Ratio of Cy $\left(I_{N p}\right)$ divided by $\mathrm{Cy}(\mathrm{Sa})$ for the normalized hysteretic energy UAFR spectra for the elasto-perfectly plastic model with annual failure rate equal to 0.004 and different values of $E_{N}$.

\section{Conclusions}

In this study, ductility and dissipated hysteretic energy UAFR spectra have been computed and compared using spectral acceleration at first mode of vibration and the wellknown $I_{N p}$ intensity measures. The results obtained for ductility and hysteretic energy UAFR spectra are as follows.

\subsection{Ductility.}

(i) The ductility UAFR spectra when $S a$ and $I_{N p}$ are used as intensity measures were computed. It was observed that as the ductility increases, the required lateral resistance decreases, where the largest differences occurred for structures close to the soil period. Therefore, the structures with vibration period close to the soil period require special attention; in particular, this type of building is more sensitive to the ductility capacity.

(ii) The influence of post-yielding stiffness also is analyzed. It was observed that the ductility spectra are very similar for the selected hysteretic models with different post-yielding stiffness, in such a way that the elasto-perfectly plastic behavior model can give reasonable results for estimating the $\mathrm{Cy}$ with bilinear behavior and different percentages of postyielding stiffness.

(iii) In the case of the influence of the annual failure rate in the UAFR spectra, it was found that as the annual failure rates are reduced, the $\mathrm{Cy}$ increases in a reasonable rate. For this reason, if the designed buildings require larger structural reliability levels, it is necessary to increase the required lateral resistance.

(iv) Finally, for the case of ductility UAFR spectra, the results suggest that for structures with low ductility capacity such as masonry or reinforced concrete buildings, the selection of an appropriate intensity measure is very important at least when several ground motion records are used to compute the average spectrum.

\subsection{Normalized Hysteretic Energy.}

(i) For the case of normalized hysteretic energy UAFR spectra and both intensity measures used, it is concluded that as the $E_{\mathrm{N}}$ increases, the required lateral resistance decreases, particularly in the region of periods close or larger to the soil period. Notice that the same trend is observed for all the selected post-yielding stiffness under consideration.

(ii) As in the case of ductility, no influence of the postyielding stiffness was observed to compute the average normalized hysteretic energy UAFR spectra.

(iii) As it was expected, as the annual failure rate decreases (structures with large reliability levels) the required lateral resistance increases.

(iv) Finally, the use of the intensity measure $S a\left(T_{1}\right)$ could provide a lateral resistance that produces unsafety structural designs accounting for cumulative plastic deformation demands. In other words, for energy-based design or energy-based spectra it is concluded that $I_{N p}$ should be used as intensity measure.

\section{Data Availability}

The data used to support the findings of this study are available from the corresponding authors upon request.

\section{Conflicts of Interest}

The authors declare that there are no conflicts of interest regarding the publication of this study.

\section{Acknowledgments}

The financial support given by the Universidad Autónoma de Sinaloa under Grant PROFAPI 2022 is appreciated. The authors express their gratitude to the Consejo Nacional de Ciencia y Tecnología (CONACYT) in Mexico for funding the research reported in this study under Grant Ciencia Básica 287103 and for the scholarships given to the $\mathrm{PhD}$ students. The support of the UNAM-DGAPA-PAPIIT under Project No. IN100320 is appreciated.

\section{References}

[1] N. Buratti, "A comparison of the performances of various ground-motion intensity measures," in Proceedings of the the 15th World Conference on Earthquake Engineering, pp. 24-28, Lisbon, Portugal, September, 2012.

[2] E. Bojórquez, I. Iervolino, A. Reyes-Salazar, and S. E. Ruiz, "Comparing vector-valued intensity measures for fragility analysis of steel frames in the case of narrow-band ground motions," Engineering Structures, vol. 45, pp. 472-480, 2012. 
[3] M. De Biasio, S. Grange, F. Dufour, F. Allain, and I. PetreLazar, "A simple and efficient intensity measure to account for nonlinear structural behavior," Earthquake Spectra, vol. 30, no. 4, pp. 1403-1426, 2014.

[4] M. Kohrangi, S. R. Kotha, and P. Bazzurro, "Ground-motion models for average spectral acceleration in a period range: direct and indirect methods," Bulletin of Earthquake Engineering, vol. 16, no. 1, pp. 45-65, 2017.

[5] E. Bojórquez and I. Iervolino, "Spectral shape proxies and nonlinear structural response," Soil Dynamics and Earthquake Engineering, vol. 31, no. 7, pp. 996-1008, 2011.

[6] N. Buratti, Confronto tra le performance di diverse misure di intensitá dello scuotimento sísmico, Congreso Nacional de Ingeniería de Italia, ANIDIS, Pisa, Italia, 2011.

[7] A. Modica and P. J. Stafford, "Vector fragility surfaces for reinforced concrete frames in Europe," Bulletin of Earthquake Engineering, vol. 12, no. 4, pp. 1725-1753, 2014.

[8] M. Yakhchalian, A. Nicknam, and G. G. Amiri, "Optimal vector-valued intensity measure for seismic collapse assessment of structures," Earthquake Engineering and Engineering Vibration, vol. 14, no. 1, pp. 37-54, 2015.

[9] K. Kostinakis and A. Athanatopoulou, "Incremental dynamic analysis applied to assessment of structure-specific earthquake IMs in 3D R/C buildings," Engineering Structures, vol. 125, pp. 300-312, 2016.

[10] H. R. Jamshidiha, M. Yakhchalian, and B. Mohebi, "Advanced scalar intensity measures for collapse capacity prediction of steel moment resisting frames with fluid viscous dampers," Soil Dynamics and Earthquake Engineering, vol. 109, pp. 102-118, 2018.

[11] S. Minas and C. Galasso, "Accounting for spectral shape in simplified fragility analysis of case-study reinforced concrete frames," Soil Dynamics and Earthquake Engineering, vol. 119, pp. 91-103, 2019.

[12] G. W. Housner, "Limit design of structures to resist earthquakes," in Proceedings of the First World Conference on Earthquake Engineering, Berkeley, CA, USA, June, 1956.

[13] H. Akiyama, Earthquake-Resistant Limit-State Design for Buildings, University of Tokyo Press, Tokyo, Japan, 1985.

[14] C.-M. Uang and V. V. Bertero, "Evaluation of seismic energy in structures," Earthquake Engineering \& Structural Dynamics, vol. 19, no. 1, pp. 77-90, 1990.

[15] B. Akbas, J. Shen, and H. Hao, "Energy appproach in peformance-based seismic design of steel moment resisting frames for basic safety objective," The Structural Design of Tall Buildings, vol. 10, no. 3, pp. 193-217, 2001.

[16] L. D. Decanini and F. Mollaioli, "An energy-based methodology for the assessment of seismic demand," Soil Dynamics and Earthquake Engineering, vol. 21, no. 2, pp. 113-137, 2001.

[17] H. Choi and J. Kim, "Energy-based seismic design of bucklingrestrained braced frames using hysteretic energy spectrum," Engineering Structures, vol. 28, no. 2, pp. 304-311, 2006.

[18] E. Bojórquez, A. Reyes-Salazar, A. Terán-Gilmore, and S. E. Ruiz, "Energy-based damage index for steel structures," Steel and Composite Structures, vol. 10, pp. 331-348, 2009.

[19] Y. Lieping, C. Guangy, and Q. Zhe, "Study on energy-based seismic design method and the application for steel braced frame structures," in Proceedings of the Sixth International Conference on Urban Earthquake Engineering, Tokyo Institute of Technology, Tokyo, Japan, March, 2009.

[20] M. G. Mezgebo and E. M. Lui, "A new methodology for energy-based seismic design of steel moment frames," Earthquake Engineering and Engineering Vibration, vol. 16, no. 1, pp. 131-152, 2017.
[21] A. Teran-Gilmore and J. O. Jirsa, "Energy demands for seismic design against low-cycle fatigue," Earthquake Engineering \& Structural Dynamics, vol. 36, no. 3, pp. 383-404, 2007.

[22] E. Bojorquez, S. E. Ruiz, and A. Teran-Gilmore, "Reliabilitybased evaluation of steel structures using energy concepts," Engineering Structures, vol. 30, no. 6, pp. 1745-1759, 2008.

[23] T. Inoue and C. A. Cornell, "Seismic hazard analysis of MDOF structures," in Proceedings of the International Conference on Acoustics, Speech and Signal Processing 6, vol. 1, pp. 437-444, Ciudad de México, México, April, 1991.

[24] L. Esteva, S. E. Ruiz, and J. L. Rivera, "Reliability and performance-based design of structures with energy-dissipating devices," in Proceedings of the 9th World Seminar on Seismic Isolation, Energy Dissipation and Active Vibration Control of Structures, Kobe, Japan, June 2005.

[25] E. Bojorquez, J. Bojorquez, S. E. Ruiz, A. Reyes-Salazar, and J. Velazquez-Dimas, "Response transformation factors for deterministic-based and reliability-based seismic design," Structural Engineering and Mechanics, vol. 46, pp. 755-773, 2013.

[26] Y. K. Wen, "Building reliability and code calibration," Earthquake Spectra, vol. 11, no. 2, pp. 269-296, 1995.

[27] C. A. Cornell, "Reliability-based earthquake-resistant design: the future," in Proceedings of the 11th World Conference on Earthquake Engineering, Balkema Rotterdam, Acapulco, Mexico, June 1992.

[28] F. Naeim, A. Alimoradi, and S. Pezeshk, "Selection and scaling of ground motion time histories for structural design using genetic algorithms," Earthquake Spectra, vol. 20, no. 2, pp. 413-426, 2004.

[29] X. Ye and D. Wang, "Selection of real earthquake accelerograms for structural dynamic analysis and energy evaluation," Science China Technological Sciences, vol. 54, no. 11, pp. 2878-2885, 2011.

[30] I. Iervolino, C. Galasso, R. Paolucci, and F. Pacor, "Engineering ground motion record selection in the Italian accelerometric archive," Bulletin of Earthquake Engineering, vol. 9, no. 6, pp. 1761-1778, 2011.

[31] E. Bojórquez, A. Reyes-Salazar, S. E. Ruiz, and J. Bojórquez, "A new spectral shape-based record selection approach using and genetic algorithms," Mathematical Problems in Engineering, vol. 2013, Article ID 679026, 9 pages, 2013.

[32] R. K. Mohammadi, M. Mirtaheri, M. Salkhordeh, E. Mosaffa, G. Mahdavi, and M. A. H. Ardebili, "Seismic mitigation of substation cable connected equipment using friction pendulum systems," Structural Engineering \& Mechanics, vol. 72, no. 6, pp. 785-796, 2019.

[33] M. Salkhordeh, E. Govahi, and M. Mirtaheri, "Seismic fragility evaluation of various mitigation strategies proposed for bridge piers," Structure, vol. 33, pp. 1892-1905, 2021.

[34] L. Esteva, "Criterios para la construcción de espectros para diseño por sismo," in Boletín del Instituto de Materiales y Modelos EstructuralesUniversidad Central de Venezuela, Caracas, Venezuela, 1967.

[35] C. A. Cornell, "Engineering seismic risk analysis," Bulletin of the Seismological Society of America, vol. 58, no. 5, pp. 1583-1606, 1968.

[36] S. H. Hartzell, "Simulation of ground accelerations for may 1980 mammoth lakes California earthquakes," Bulletin of the Seismological Society of America, vol. 72, pp. 2381-2387, 1982.

[37] K. Irikura, Semi-Empirical Estimation of Strong Ground Motions During Large Earthquakes, Bulletin of the Disaster Prevention Research Institute, Kyoto, Japan, 1983. 
[38] S. H. Hartzell, "Earthquake aftershocks as Green functions," Geophysical Research Letters, vol. 5, pp. 1-4, 1978.

[39] M. Niño, G. Ayala, and M. Ordaz, "Ground-motion simulation by the empirical Green's function method with a source defined by two corner frequencies and a two-stage summation scheme," Bulletin of the Seismological Society of America, vol. 108, no. 2, pp. 901-912, 2018.

[40] M. Ordaz, J. Arboleda, and K. Singh, "A scheme of random summation of an empirical Green's function to estimate ground motions from future large earthquake," Bulletin of the Seismological Society of America, vol. 85, pp. 1635-1647, 1995.

[41] D. García, K. Singh, M. Herraiz, F. Pacheco, and M. Ordaz, "Inslab earthquakes of central Mexico: Q, source spectra and stress drop," Bulletin of the Seismological Society of America, vol. 94, no. 3, pp. 789-802, 2004.

[42] R. J. Archuleta and C. Ji, "Moment rate scaling for earthquakes $3.3 \leq \mathrm{M} \leq 5.3$ with implications for stress drop," Geophysical Research Letters, vol. 43, no. 12, pp. 4-12, 2016.

[43] E. Javadi and M. Yakhchalian, "Selection of optimal intensity measure for seismic assessment of steel buckling restrained braced frames under near-fault ground motions," Journal of Rehabilitation in Civil Engineering, vol. 7-4, pp. 1-20, 2018.

[44] H. Krawinkler and A. Nassar, "Seismic design based on ductility and cumulative damage demands and capacities," in Nonlinear Seismic Analysis and Design of Reinforced Concrete Buildings, H. Krawinkler and P. Fajfar, Eds., Elsevier Applied Science, London, U.K., 1992.

[45] A. Teran-Gilmore and R. Simon, "Use of constant cumulative ductility spectra for performance-based seismic design of ductile frames," in Proceedings of the 8th U.S. National Conference on Earthquake Engineering, San Francisco, CA, USA, April 2006.

[46] D. Vamvatsikos and C. A. Cornell, "Incremental dynamic analysis," Earthquake Engineering \& Structural Dynamics, vol. 26, no. 3, pp. 701-716, 2002.

[47] E. Bojórquez, A. Terán-Gilmore, S. E Ruiz, and A. ReyesSalazar, "Evaluation of structural reliability of steel frames: interstory drift versus plastic hysteretic energy," Earthquake Spectra, vol. 27, no. 3, pp. 661-682, 2011.

[48] A. Rodríguez-Castellanos, S. E. Ruiz, E. Bojórquez, and A. Reyes-Salazar, "Influence of spectral acceleration correlation models on conditional mean spectra and probabilistic seismic hazard analysis," Earthquake Engineering \& Structural Dynamics, vol. 50, pp. 1-20, 2020.

[49] A. Rodríguez-Castellanos, S. E. Ruiz, E. Bojórquez, M. A. Orellana, and A. Reyes-Salazar, "Reliability-based strength modification factor for seismic design spectra considering structural degradation," Natural Hazards and Earth System Sciences, vol. 21, pp. 1445-1460, 2021.

[50] R. K. McGuire, "Probabilistic seismic hazard analysis and design earthquakes: closing the loop," Bulletin of the Seismological Society of America, vol. 85, no. 5, pp. 1275-1284, 1995.

[51] S. L. Kramer, Geotechnical Earthquake Engineering, PrenticeHall, Hoboken, NJ, USA, 1996.

[52] J. W. Baker, Probabilistic Seismic Hazard Analysis, Independently Published, Chicago, Illinois, 2013. 